\title{
Comparison of thermal behavior of natural and hot-washed sisal fibers based on their main components: cellulose, xylan and lignin. TG-FTIR analysis of volatile products
}

\author{
Mónica Benítez-Guerrero ${ }^{1 *}$, Jorge López-Beceiro ${ }^{2}$, Pedro E. Sánchez-Jiménez ${ }^{3}$ and José Pascual-Cosp ${ }^{1}$. \\ ${ }^{1}$ Departamento de Ingeniería Civil, Materiales y Fabricación, Universidad de Málaga, Escuela de Ingenierías. C/ Dr. \\ Ortiz Ramos s/n. Campus Teatinos. 29071 Málaga. Spain. \\ ${ }^{2}$ Departamento de Ingeniería Industrial II. Escola Politécnica Superior. Universidade da Coruña, Avda. Mendizábal, \\ 15403 Ferrol, Spain. \\ ${ }^{3}$ Instituto de Ciencia de Materiales de Sevilla, CSIC-Universidad de Sevilla, C. Américo Vespucio 49, 41092 Sevilla, \\ Spain \\ *Corresponding author. Email: monica_benitez_guerrero@yahoo.es
}

Tel: +34951952594 Fax: +34951952601

\section{Abstract:}

This paper presents in a comprehensive way the thermal behavior of natural and hot-.washed sisal fibers, based on the fundamental components of lignocellulosic materials: cellulose, xylan and lignin. The research highlights the influence exerted on the thermal stability of sisal fibers by other constituents such as non-cellulosic polysaccharides (NCP) and mineral matter.

Thermal changes were investigated by thermal X-ray diffraction (TXRD), analyzing the crystallinity index (\%Ic) of cellulosic samples, and by simultaneous thermogravimetric and differential thermal analysis coupled with Fourier-transformed infrared spectrometry (TG/DTA-FTIR), which allowed to examine the evolution of the main volatile compounds evolved during the degradation under inert and oxidizing atmospheres. The work demonstrates the potential of this technique to elucidate different steps during the thermal decomposition of sisal, providing extensible results to other lignocellulosic fibers, through the analysis of the evolution of $\mathrm{CO}_{2}, \mathrm{CO}, \mathrm{H}_{2} \mathrm{O}, \mathrm{CH}_{4}$, acetic acid, formic acid, methanol, formaldehyde and 2-butanone, and comparing it with the volatile products from pyrolysis of the biomass components. The hydroxyacetaldehyde detected during pyrolysis of sisal is indicative of an alternative route to that of levoglucosan, generated during cellulose pyrolysis.

Hot-washing at $75{ }^{\circ} \mathrm{C}$ mostly extracts non-cellulosic components of low decomposition temperature, and reduces the range of temperature in which sisal decomposition occurs, causing a retard in the pyrolysis stage and increasing $\mathrm{Tb}_{\mathrm{NCP}}$ and $\mathrm{Tb}_{\mathrm{CEL}}$, temperatures at the maximum mass loss rate of non-cellulosic polysaccharides and cellulose decompositions, respectively. However, enriching sisal fibers in cellulose produces a decrease of $\mathrm{Tb}_{\mathrm{CEL}}$ under an oxidizing atmosphere, and furthermore, a delay of the combustion process, displacing $\mathrm{Tb}_{\mathrm{COM}}$ to higher temperatures.

The results and findings of the paper would help further understanding of thermal processes where agave fibers are involved, as the decomposition of their composites.

Keywords: Sisal fiber; Hot-water treatment; Biomass components; TGA-FTIR; Gas evolution; Pyrolysis; Combustion. 


\section{Introduction}

The large number and diversity of lignocellulosic products as well as plurality of their applications in many industrial sectors, implies the need to comprehensively know their thermal behavior, stability and degradation processes at elevated temperatures.

Pyrolysis studies of synthetic biomass, obtained by mixing its fundamental constituents, revealed that, in general, the overall degradation of biomass follows the principle of additivity [1,2]. However, different authors $[3,4]$ show that interaction among the constituents exits, whereby the proportion of the pyrolysis products differs from that of natural biomass.

It has been demonstrated that the addition of extractives and mineral compounds to the fundamental biomass components [5-7], and the degree of crystallinity of cellulose [8], affect the pyrolysis process. The influence of extractives and mineral matter on thermal decomposition of different lignocellulosic materials has been studied extensively [9-11]. Water washing is a simple and economical pretreatment, which has been used to remove alkali metals from biomass, to avoid the toxicity of mists generated by the combustion of biomass, so preventing accumulation problems (deposition, corrosion, erosion, etc.) in combustion and gasification plants, and also to improve process yields [12-14]. Hot washing process reduces the proportion of substances adhered to the cell walls, removing organic compounds, as a hemicellulose fraction and other low molecular weight carbohydrates, and minerals such as salts of alkali, alkaline earth and transition metal cations.

In addition to the traditional purposes, the use of Agave species fibers has spread to a variety of processes of interest in many industrial sectors, due to their ease of cultivation, with high productivity and low cost associated, as well as their renewable and biodegradable character. Furthermore, their biomass component proportion makes them suitable for processability and biofuel production [15,16]. In particular, Agave sisalana fiber or sisal fiber is one of the most widely used due to its good mechanical properties, used in a great variety of traditional applications due to its hardness, coarseness and resistance to wear, which has gained great interest during the last decades in the manufacturing of composite materials, particularly as reinforcement of mortars, concrete and polymeric matrices [17-19], as polypropylene [20-22].

Sisal fibers are mainly composed of cellulose and non-cellulosic polysaccharides (NCP): hemicellulose O-acetyl-(4-O-methylglucurono)xylan [23] and pectins composed of rhamnose, arabinose and uronic acid at a 2.3:1:3.3 ratio [24], along with a smaller amount of lignin, whose molar ratio of constitutional units, p-hydroxyl phenol $(\mathrm{H})$, guaiacyl $(\mathrm{G})$ and syringyl $(\mathrm{S})$, has been established in $2 \% \mathrm{H}$, $22 \% \mathrm{G}$ and $76 \% \mathrm{~S}$ [25]. Furthermore, the fiber is constituted by a lower proportion of extractives, such as lipophilic components [26], simple phenolic derivatives and mineral matter, mainly represented by calcium oxalate deposits located between the elementary fibers comprising the fiber bundle [27]. The composition of sisal, as any natural fiber, varies depending on the origin, age and extraction process of the components, among other factors. The compositional variability in terms of constituents is very large as can be deduced from different reviews $[15,28,29]$.

There is a lot of information scattered in the literature about the thermal behavior of sisal fibers, but few studies have analyzed it in depth [30-32]. The extensive work recently published by Martin et al. 
[33] focuses on the thermal decomposition of sisal and the main biocomponents extracted from the fiber itself. However, given the complexity of thermal processes occurring in lignocellulosic materials, the comparison of thermogravimetric stages with their associated energy effects requires a detailed analysis, interpreted through the analysis of the decomposition of pure biomass components, adding a new perspective that would allow for a better definition of the phenomena occurring. Furthermore, the evolution of the thermal degradation products of sisal fibers is poorly described. Only the liquid fraction released during fast pyrolysis has been characterized [34], there being a lack of information about the gaseous products emitted.

The thermogravimetry coupled with Fourier-transformed infrared spectroscopy (TG-FTIR) technique has been proved to be a valuable and simple tool, not only to analyze the gas phase during the thermolysis of lignocellulosic compounds [35-37], but also to clarify different steps during fiber decomposition.

This paper aims to analyze and present in a comprehensive way the thermal behavior of natural and hot washed sisal fibers, discussing their thermogravimetric and differential thermal analysis (TGDTA) on the basis of the degradation of fundamental components, cellulose, lignin and xylan, and comparing the evolution of the gas phase decomposition products by TG-FTIR analysis.

\section{Materials and Methods}

The sisal fibers used in this work were provided by Cayetano García del Moral S. L. (Cabra de Santo Cristo, Jaén, Spain). They were cut to 2 - $4 \mathrm{~mm}$ length and then subjected to a washing process with stirring in hot water at $75{ }^{\circ} \mathrm{C}$ for 2 hours. Hereinafter the samples will be referred to as Natural Sisal and Washed Sisal. Microcrystalline cellulose powder (Aldrich), alkali low sulfonate content lignin (Sigma Aldrich) and birch xylan (xylose $\geq 90 \%$, Aldrich) were used as representatives of the main biomass components.

X-ray diffraction (XRD) measurements were performed in a Philips X'Pert PRO MPD, with a $\mathrm{X}^{\prime}$ Celerator real time multiple strip RTMS system. Thermodiffraction was performed in Helium atmosphere at temperatures up to $400{ }^{\circ} \mathrm{C}$, using a TTK450N chamber for Aldrich cellulose and a one HTK1200N for Natural Sisal. Spectra were acquired every $20^{\circ} \mathrm{C}$, each one was recorded for 50 minutes in the $2 \theta$ range from 5 to $45^{\circ}$. Temperature was linearly changed between isotherms at $5{ }^{\circ} \mathrm{C} / \mathrm{min}$, and the stabilization time at each isotherm was 5 minute. Data were analyzed employing X'Pert HighScore software. The crystallinity index, \% $\mathrm{Ic}(\mathrm{XRD})$, was calculated at several temperatures using the equation proposed by Segal [38]:

$$
\% I_{c}(X R D)=1-\frac{I_{a m}}{I_{\max }} \times 100
$$

where $I_{\max }$ is the maximum intensity of the (002) lattice reflection of cellulose $\mathrm{I}_{\beta}$ type, located at $2 \theta$ between 22 and $23^{\circ}$, and $I_{a m}$ is the intensity attributed to amorphous part, given at $2 \theta$ between $18^{\circ}$ and $19^{\circ}$ for $\mathrm{I}_{\beta}$ cellulose. 
Thermogravimetric study was performed in a TA Instruments STD 2960 simultaneous thermal analyzer. The experimental setup consisted of a $10{ }^{\circ} \mathrm{C} / \mathrm{min}$ linear heating program from 20 to $750{ }^{\circ} \mathrm{C}$, with flow rates of 50 and $120 \mathrm{~mL} / \mathrm{min}$, both in air and in nitrogen. The gases released were immediately analyzed in a Bruker VECTOR 22 infrared spectrometer, coupled to the outlet port of the SDT. The transfer line and the cell were kept to a temperature of $200{ }^{\circ} \mathrm{C}$. The spectrum of the evolved gas was recorded every 61 seconds, and consists of an average of 64 scans with a resolution of $4 \mathrm{~cm}^{-1}$ in the range from 4000 to $500 \mathrm{~cm}^{-1}$. Spectra were analyzed using Bruker OPUS 5.5 software, being baseline-corrected by a concave rubber band algorithm computed with 10 iterations on 64 points.

Ashes from the combustion of natural and washed sisal fibers were semi quantitatively analyzed by X-ray fluorescence, using a PANalytical AXIOS spectrometer.

\section{Results and Discussion}

\subsection{Evolution of the crystallinity index of cellulose and sisal}

The diffraction patterns at different temperatures of microcrystalline cellulose and Natural Sisal are shown in Fig. 1. At room temperature, cellulose clearly presents reflections around $2 \theta=15,16.5$, $20.5,22.5$ and $34.5^{\circ}$, corresponding respectively to the planes $(101),\left(10^{\overline{1}}\right),(021),(002)$ and $(040)$ of $I_{\beta}$ type allomorph, while sisal fiber only exhibits the main (002) peak, and a convolution of (101)-(10 $\overline{1})$ reflections, which are superimposed to calcium oxalate hydrate $\mathrm{Ca}(\mathrm{COO})_{2} \cdot \mathrm{H}_{2} \mathrm{O}$ ones (pattern 20-0231 of the Joint Committee on Powder Diffraction Standards - International Center for Diffraction Data, JCPDS - ICDD). For both, it is observed that the intensity of reflections decreases with increasing temperature, shifting the diffraction peaks towards a greater spacing. It can be explained due to the progressive deterioration of cellulose crystal lattice, until the structure becomes completely amorphous, observed before $310{ }^{\circ} \mathrm{C}$. Furthermore, the constitutive minerals of sisal fiber experiment transformations with increasing temperature, generating stable crystalline compounds under inert atmosphere.
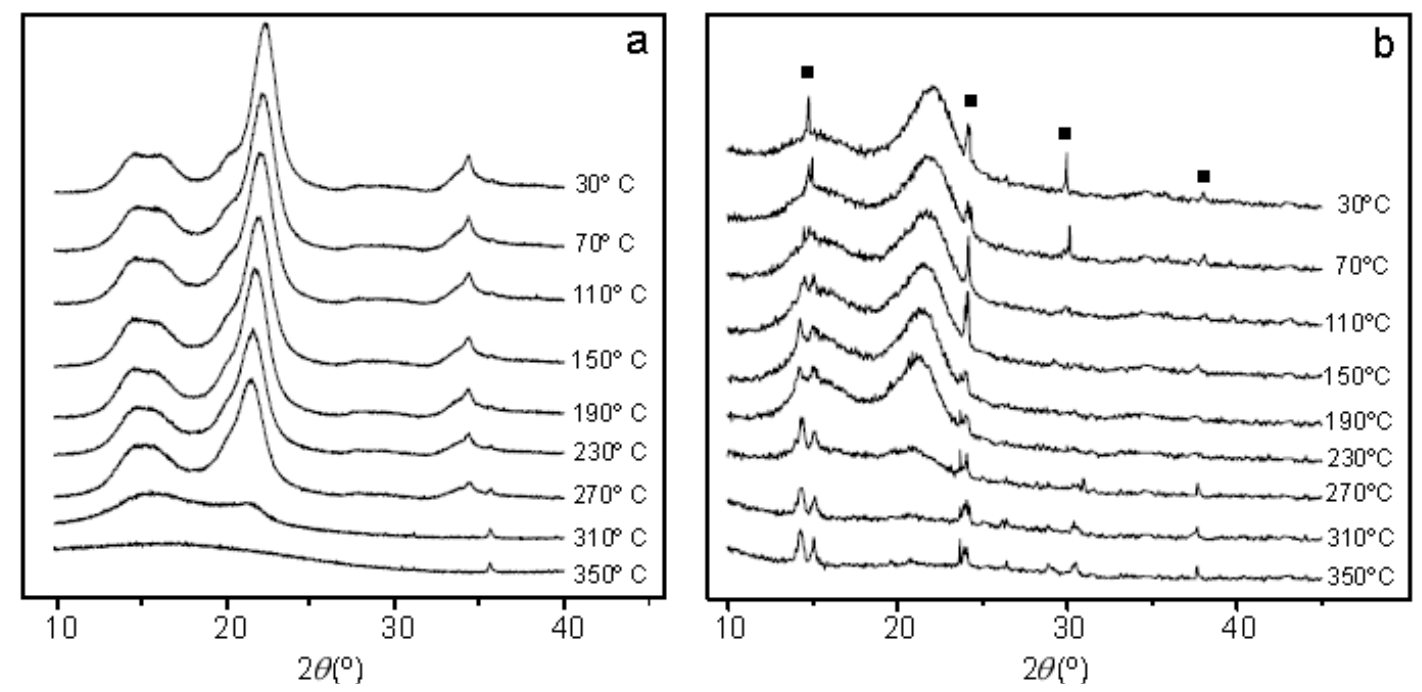

Figure 1. X-ray diffractograms at different temperatures, a of microcrystalline cellulose and $\mathbf{b}$ of Natural sisal, where can be observed reflexions from $\mathrm{Ca}(\mathrm{COO})_{2} \cdot \mathrm{H}_{2} \mathrm{O}(\mathbf{m})$. 
The evolution of \%Ic(XRD) with temperature for both cellulose and sisal is displayed in Fig. 2, being observed a much more pronounced variation for the natural fiber. A rapid decrease occurs for sisal index at temperatures below than $100{ }^{\circ} \mathrm{C}$, remaining stable at around $42 \%$ until $210{ }^{\circ} \mathrm{C}$. In contrast, it diminishes slowly to $76 \%$ for cellulose. Near $230{ }^{\circ} \mathrm{C}$, the crystallinity index of both sisal and cellulose falls sharply, presenting almost the same slope in both cases. At $270{ }^{\circ} \mathrm{C}$ it reaches the smallest value of $17 \%$ for sisal, and $65 \%$ for the studied cellulose, which is totally amorphized above $310{ }^{\circ} \mathrm{C}$. This behavior for sisal fiber is close to that reported by Saikia [32], which describes a reduction of the degree of crystallinity from 51 to $41 \%$ when sisal is heated in air at $177^{\circ} \mathrm{C}$, becoming completely amorphous at around $260{ }^{\circ} \mathrm{C}$.

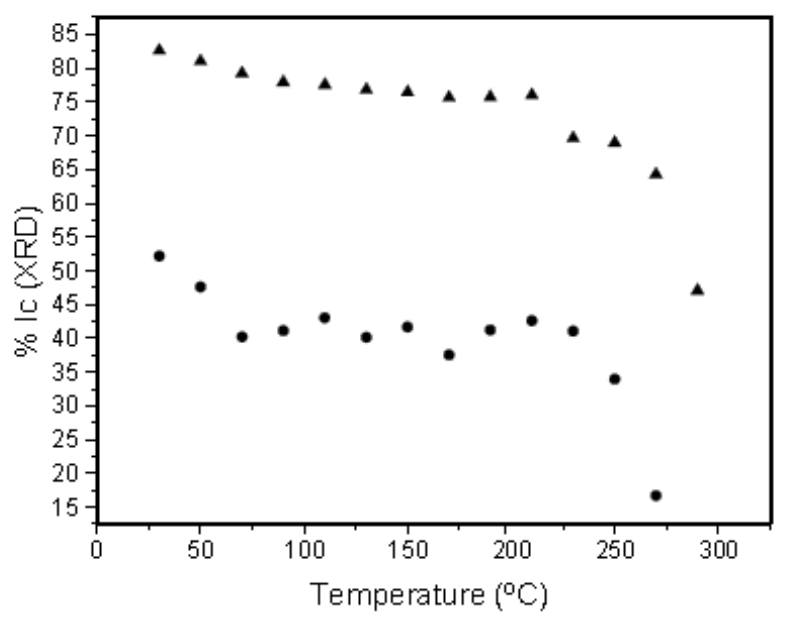

Figure 2. Variation of the crystallinity index, \% Ic(XRD), with temperature for microcrystalline cellulose $(\boldsymbol{\Delta})$ and Natural Sisal $(\bullet)$.

\subsection{TG-DTG/DTA analysis of the biomass components}

Previously to the analysis of the thermal decomposition of sisal fibers, it is important to understand the behavior of the main lignocellulosic components. Figure 3 exhibits TG, DTG and DTA plots for the studied cellulose, xylan, and lignin, under both air and nitrogen atmospheres. Temperature ranges, temperature of maximum mass loss rate $(\mathrm{Tb})$ and the mass loss on a dry basis are summarized in Table 1. The weight on dry basis is calculated from each thermogram excluding the mass loss below $180^{\circ} \mathrm{C}$ 

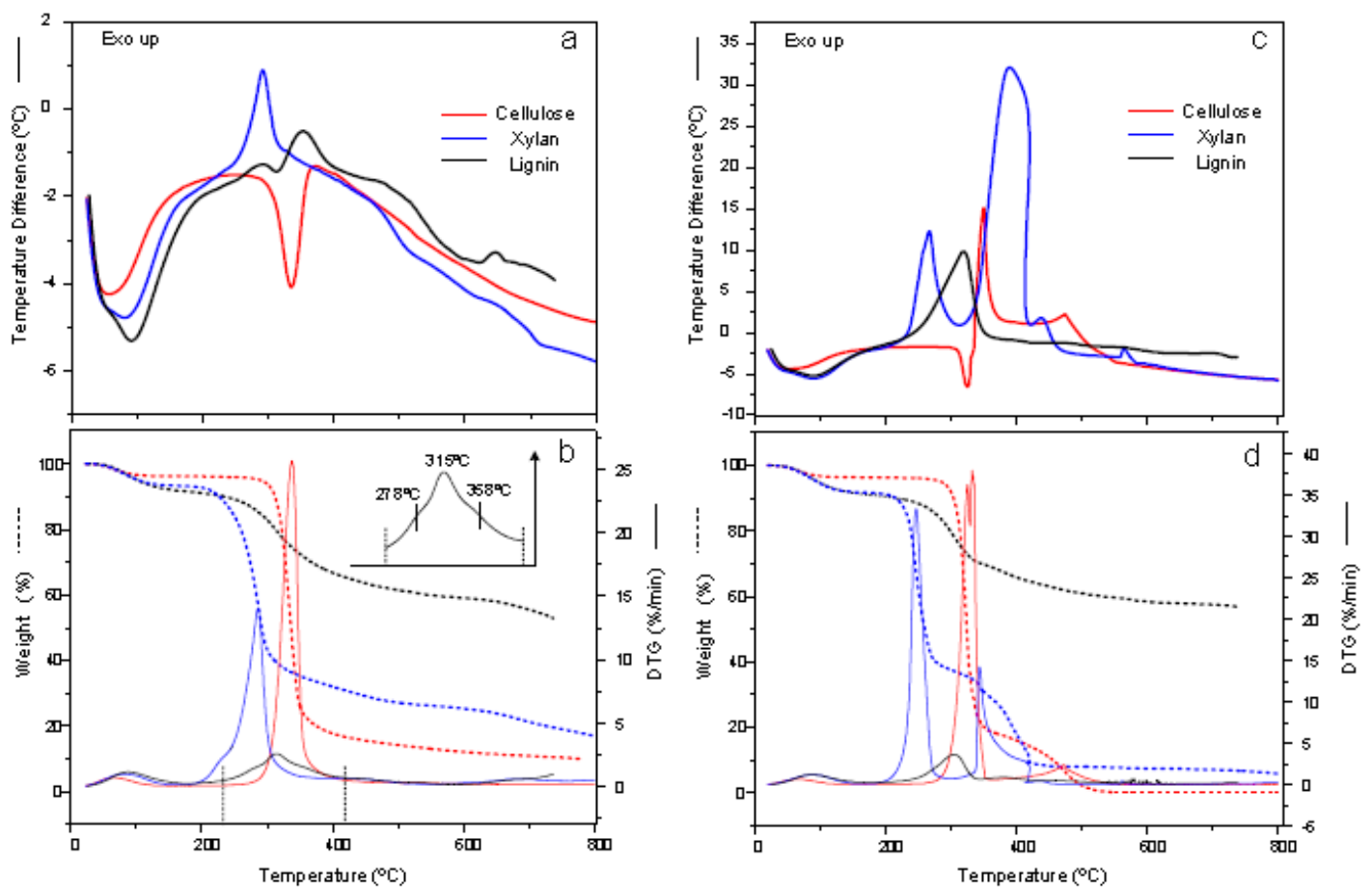

Figure 3. TG/DTG-DTA thermograms of the main biomass components, under nitrogen (a-b) and air purges (c-d) with flow rates of $120 \mathrm{~mL} / \mathrm{min}$. The inner inset in Fig. $3 \mathrm{~b}$ notes three superimposed stages on DTG curve of lignin.

Table 1: Thermoanalytical data TG/DTG-DTA of biomass components, under air and nitrogen atmospheres $(120 \mathrm{~mL} / \mathrm{min}$ flow rate).

\begin{tabular}{|c|c|c|c|c|c|c|c|c|}
\hline & \multicolumn{4}{|c|}{ Air } & \multicolumn{4}{|c|}{ Nitrogen } \\
\hline & & $\mathrm{Tb}^{a}\left({ }^{\circ} \mathrm{C}\right)$ & $\% w t^{b}$ & $\begin{array}{c}T_{\text {peak }}\left({ }^{\circ} \mathrm{C}\right) \\
\text { DTA }\end{array}$ & & $T b^{a}\left({ }^{\circ} \mathrm{C}\right)$ & $\% w t^{b}$ & $\begin{array}{c}T_{\text {peak }}\left({ }^{\circ} \mathrm{C}\right) \\
D T A\end{array}$ \\
\hline \multirow{5}{*}{ 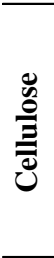 } & $21-185$ & 65 & & 52 endo & $23-200$ & 66 & \multirow{4}{*}{83.8} & 56 endo \\
\hline & $185-329$ & 325 & 61.9 & 325 endo & \multirow{3}{*}{$200-447$} & \multirow{3}{*}{338} & & \multirow{4}{*}{$\begin{array}{l}335 \text { endo } \\
400 \text { exo }\end{array}$} \\
\hline & $329-354$ & 333 & 17.9 & 350 exo & & & & \\
\hline & $354-737$ & 473 & 19.9 & 475,600 exo & & & & \\
\hline & Ash $\left(737^{\circ} \mathrm{C}\right)$ & & 0.3 & & \multicolumn{2}{|c|}{ Residue $\left(737^{\circ} \mathrm{C}\right)$} & \multirow[t]{2}{*}{10.8} & \\
\hline \multirow{6}{*}{$\frac{1}{\sqrt{x}}$} & $20-165$ & 88 & & \multirow{6}{*}{$\begin{array}{l}90 \text { endo } \\
268 \text { endo } \\
390 \text { exo } \\
438 \text { exo } \\
565 \text { exo }\end{array}$} & $23-161$ & 85 & & \multirow[t]{2}{*}{80 endo } \\
\hline & $165-298$ & 247 & 58.9 & & $161-242$ & 228 & 7.2 & \\
\hline & $298-423$ & 344 & 31.2 & & $242-362$ & 286 & 56.0 & 291 exo \\
\hline & $423-502$ & 435 & 1.3 & & $362-548$ & 460 & 8.8 & 458 exo \\
\hline & $502-653$ & 562 & 0.7 & & & & & \\
\hline & Ash $\left(737^{\circ} \mathrm{C}\right)$ & & 7.3 & & Residue $\left(737^{\circ} \mathrm{C}\right.$ & & 20.8 & \\
\hline \multirow{6}{*}{ 罪 } & $26-180$ & 86 & & 98 endo & $26-176$ & 88 & & 90 endo \\
\hline & $180-344$ & 305 & 22.8 & 319 exo & \multirow{2}{*}{\multicolumn{2}{|c|}{$176-414$ (278) $315(358)$}} & \multirow{2}{*}{28.2} & \multirow{2}{*}{$\begin{array}{l}\text { (292 exo) } 312 \text { endo } \\
\text { (353 exo) }\end{array}$} \\
\hline & $344-426$ & 380 & 6.6 & 403 exo & & & & \\
\hline & $426-737$ & 456 & 8.1 & & $414-486$ & 453 & 4.2 & 478 exo \\
\hline & & & & & $486-737$ & 678 & 9.9 & 647 exo \\
\hline & Ash $\left(737^{\circ} \mathrm{C}\right)$ & & 62.5 & & Residue $\left(737^{\circ} \mathrm{C}\right.$ & & 57.7 & \\
\hline
\end{tabular}

a DTG peak temperature

$b$ mass loss percentage and ash/residue percentage in dry base 
It can be distinguished fundamentally three stages, described underneath.

i) In the low temperature range, below $180^{\circ} \mathrm{C}$, fundamentally physically adsorbed water evaporates. The mass losses account for about $4 \%$ for cellulose, $7 \%$ for xylan and $9 \%$ for lignin. The process implies a large endothermic effect with DTA peaks under nitrogen atmosphere at 56,80 and $90{ }^{\circ} \mathrm{C}$, respectively

ii) Between 200 and $400{ }^{\circ} \mathrm{C}$ processes of depolymerization, decomposition and rearrangement occur, involving a considerable mass loss. Chemical bonds of the starting biomass break (primary reaction), generating a reactive residue (reactive char) plus liquid (tar) and gaseous compounds, taking place under inert and air atmosphere by different mechanisms, pyrolysis and oxidative pyrolysis respectively. The last one explains an accelerated decomposition in the presence of oxygen, related to oxidative type reactions described for cellulose [39,40] and for lignin [41], which in turn results in the advancement of the maximum rate of decomposition. At this stage, endothermal volatilization and exothermal charring processes are responsible of the resulting energy balance $[42,43]$.

Comparing biomass components, xylan decomposes at lower temperatures, followed by cellulose, while lignin does it over a wider range of temperatures, due to its heterogeneous structure, comprising aromatic rings with multiple branches and functional groups, whose bonds cleave along a wide range of temperature.

Two sub-stages of exothermic nature can be observed in hemicellulose decomposition. The first one, very slight with $\mathrm{Tb}$ at around $228^{\circ} \mathrm{C}$, can be associated to the decomposition of residual side chains, still present in the commercial xylan, assigned to the decomposition of 4-O-methyl glucuronic acid and acetyl groups of xylan by Shen et al. [44], while the second sub-stage, located at around $286^{\circ} \mathrm{C}$, is due to rupture of the xylan main chain. These sub-stages are hardly distinguishable in air, where the decomposition process occurs at much higher speed than in inert atmosphere.

Cellulose is the biomass component which presents the maximum mass loss and maximum mass loss rate. Pyrolysis of cellulose can be described in a simplified form as a mechanism of chain depolymerization via transglycosylation reactions [45]. One important endothermic process is observed in nitrogen atmosphere at $\mathrm{Tb}=338{ }^{\circ} \mathrm{C}$, associated to the heat of evaporation of volatile products generated by the pyrolysis of the glycosyl units [40], and it matches with the collapse of the structure and the complete loss of the crystalline structure, as shown in Fig. 1A. In contrast, a sharper endotherm at $\mathrm{Tb}=$ $325{ }^{\circ} \mathrm{C}$ is observed in air. This shifting to lower temperature is due to the oxidative degradation of cellulose which starts at lower temperatures as a result of radical autoxidation mechanism that occurs in the presence of oxygen [39]. In air, immediately after the endothermic process, it can be distinguished a large exothermic one with $\mathrm{Tb}$ at $333{ }^{\circ} \mathrm{C}$ and maximum DTA peak at $350{ }^{\circ} \mathrm{C}$, associated to the oxidation of volatiles generated in the preceding endothermic process.

Lignin is the one of the biomass components which experiences the lower mass loss and at the lowest rate. Its thermal decomposition, in which at least three superimposed processes can be distinguished at around 278,315 and $358{ }^{\circ} \mathrm{C}$ in nitrogen atmosphere (as shown the inset of the Fig. 3B), present an overall exothermic process of greater intensity in air than in nitrogen. Furthermore, after pyrolysis stage, lignin is the component which presents the highest char content, about a $60 \%$, generated 
by condensation of the phenolic groups during its thermal degradation under inert atmosphere. The Gtype lignin used in this work probably contributes to a higher char generation due to the own nature of the biomass polymer that, in one hand, allows a high degree of crosslinking facilitated by a reduced content in methoxyl groups, which in turn increases its thermal stability, and that, on the other hand, due to the own constituent guaiacyl units, is prone to experience thermal condensation reactions [46].

iii) At temperatures higher than $350-400^{\circ} \mathrm{C}$, the thermal behavior depends on the atmosphere. Under inert gas, the structure of the products generated in the previous stage starts to change through cleavage of bonds and volatilization of heteroatoms, involved in the condensation and reorganization processes leading to the formation of products with high carbon content. This carbonization stage is accompanied by a small and gradual mass loss and by slight energy changes, as it can be respectively observed on the TG and DTA plots. In addition, the volatilized compounds undergo secondary thermolythic reactions in gas phase, which do not affect the mass of the remaining sample. The effect on the DTA signal is weak since the thermocouples of the instrument are located at the bottom of the sample and reference crucibles, relatively distant from where the evolved gases may react. Fisher et al. [47] maintain that secondary reactions can be thermally neutral, depending on the conditions under which the char is generated. In the case of cellulose, a small exothermic effect is observed next to the $338^{\circ} \mathrm{C}$ endotherm, at around $400{ }^{\circ} \mathrm{C}$, which is associated to the charring process. Milosavljevic et al. [48] claim that the charring process of the cellulose can be exothermic $(-2.6 \mathrm{~kJ} / \mathrm{g}$ referred to residual carbon), endothermic $(0.86 \mathrm{~kJ} / \mathrm{g})$ or combination of both, depending on the products generated. Similarly, exothermic effects at around 460 ${ }^{\circ} \mathrm{C}$ in the case of xylan, and at 480 and $650{ }^{\circ} \mathrm{C}$ in the case of lignin, are associated to carbonizing processes.

In the presence of oxygen, the oxidation of volatile products (homogeneous reaction) and combustion of the char (heterogeneous reaction) take place in the range between 350 and $500{ }^{\circ} \mathrm{C}$, depending on the nature of the lignocellulosic material. These exothermic phenomena appear at lower temperature and with higher intensity in xylan $\left(390^{\circ} \mathrm{C}\right)$ than in cellulose $\left(475{ }^{\circ} \mathrm{C}\right)$. In addition, small exothermic effects are observed at higher temperatures, which can be associated to residual combustion processes, accompanied by a very small mass loss, which will be discussed afterwards. However, in the case of lignin, the combustion stage does not constitute a noticeable phenomenon. It appears to pass through several consecutive mild stages, with small mass loss at $\mathrm{Tb}=380$ and $456{ }^{\circ} \mathrm{C}$. Moreover, unlike what may be expected, the percentage of the final residue of lignin is slightly greater in air than in nitrogen $(63 \%>58 \%)$. This can also be explained by several reasons: a) that a partial oxidation has occurred, generating compounds of higher molecular weight; b) that a stable char has been formed due to the elevated content in aromatics [49]; c) that the metals present in lignin oxidize, thus increasing their mass. Di Blasi [50] describes many factors that affect the reactivity of the char which could explain the elevated percentage that remain after thermal decomposition of lignin under air.

The data presented here confirm that the thermal stability of the biomass components decreases in the following order: lignin, cellulose and hemicellulose. These different behaviors are due to their different chemical composition and structure [51]. Hemicellulose has an amorphous structure, formed by 
various polysaccharides with branches of different compositions, while cellulose is a polymer composed of linear chains of glucose, with a longer range order and a degree of polymerization of ten to one hundred times higher than that of hemicellulose. However, lignin is a highly cross-linked polymer consisting of highly branched units of phenylpropane, which confers a great thermal stability.

\subsection{TG-DTG/DTA analysis of natural and hot-washed sisal fibers}

Thermal degradation of sisal and washed sisal has been studied by means of simultaneous TGDTA using purges of air and nitrogen, both at 50 and $120 \mathrm{~mL} / \mathrm{min}$. Figure 4 shows a comparison of their thermogravimetric curves in air and nitrogen. Table 2 shows the mass loss on a dry basis, ranges of temperature and maximum temperature of the mass loss rate $(\mathrm{Tb})$ of each stage.
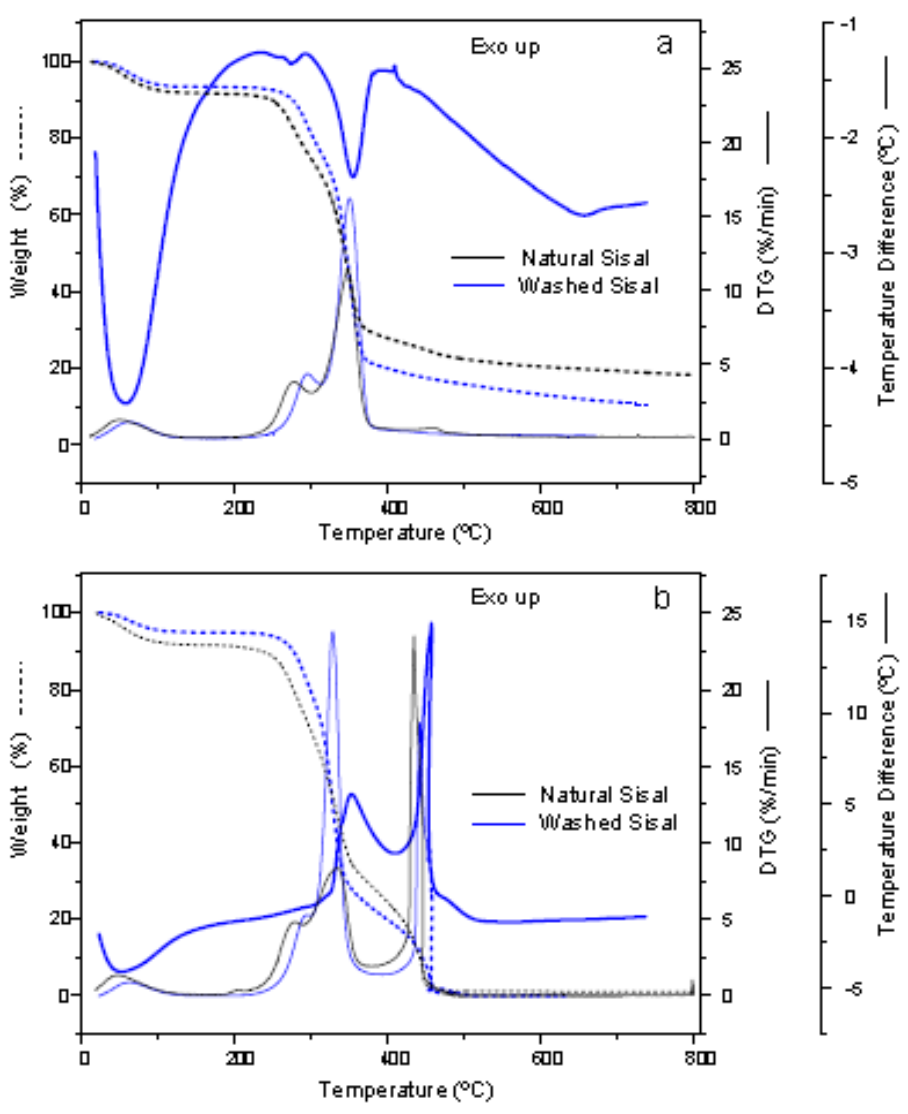

Figure 4. Comparison of TG/DTG-DTA thermograms of Natural and Washed Sisal, under $50 \mathrm{~mL} / \mathrm{min}$ flow rate. 
Table 2 Thermoanalytical data TG/DTG-DTA of Natural and Washed Sisal, under air and nitrogen.

\begin{tabular}{|c|c|c|c|c|c|c|c|c|}
\hline & \multicolumn{4}{|c|}{ Air } & \multicolumn{4}{|c|}{ Nitrogen } \\
\hline & & $T b^{a}\left({ }^{\circ} \mathrm{C}\right)$ & $\% w t^{b}$ & $\begin{array}{c}T_{\text {peak }}\left({ }^{\circ} \mathrm{C}\right) \\
D S C \\
\end{array}$ & & ${ }^{a}\left({ }^{\circ} \mathrm{C}\right)$ & $\% w t^{b}$ & $\begin{array}{c}T_{\text {peak }}\left({ }^{\circ} \mathrm{C}\right) \\
D S C \\
\end{array}$ \\
\hline \multirow{6}{*}{ 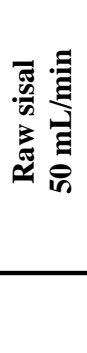 } & $20-186$ & 48 & & 52 endo & $20-158$ & 52 & & 52 endo \\
\hline & $186-294$ & (203) 281 & 21.1 & (207 exo) & $158-301$ & 279 & 18.7 & 290 exo \\
\hline & $294-380$ & 336 & 47.7 & 350 exo & $301-398$ & 336 & 50.8 & 320 exo \\
\hline & $380-487$ & 435 (471) & 29.9 & 447 (473) exo & $398-482$ & 460 & 5.4 & 470 endo \\
\hline & $\operatorname{Ash}\left(737^{\circ} \mathrm{C}\right)$ & & 1.2 & & Residue $\left(737^{\circ} \mathrm{C}\right)$ & & 20.5 & \\
\hline & & $\mathrm{Tb}^{a}\left({ }^{\circ} \mathrm{C}\right)$ & $\% w t^{b}$ & $\begin{array}{c}T_{\text {peak }}\left({ }^{\circ} \mathrm{C}\right) \\
D T A\end{array}$ & & ${ }^{a}\left({ }^{\circ} \mathrm{C}\right)$ & $\% w t^{b}$ & $\begin{array}{c}T_{\text {peak }}\left({ }^{\circ} \mathrm{C}\right) \\
\text { DTA }\end{array}$ \\
\hline \multirow{6}{*}{ 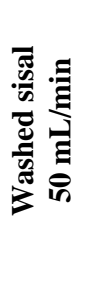 } & $24-187$ & 62 & & 53 endo & $20-171$ & 62 & & 61 endo \\
\hline & $187-301$ & 294 & 17.0 & & $171-314$ & 293 & 18.5 & 293 exo \\
\hline & $301-391$ & 329 & 60.0 & 352 exo & $314-474$ & 352 & 63.6 & 355 endo \\
\hline & $391-458$ & 442 & 21.1 & 457 exo & $474-737$ & & & 651 exo \\
\hline & $458-512$ & & 1.5 & 480 exo & & & & \\
\hline & $\operatorname{Ash}\left(737^{\circ} \mathrm{C}\right)$ & & 0.3 & & Residue $\left(737^{\circ} \mathrm{C}\right)$ & & 11.2 & \\
\hline \multirow{6}{*}{ 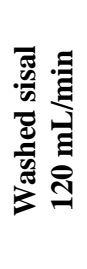 } & $26-173$ & 66 & & 58 endo & $23-170$ & 70 & & 55 endo \\
\hline & $173-301$ & 295 & 17.6 & & $170-311$ & 294 & 17.9 & 294 exo \\
\hline & $301-381$ & 328 & 58.5 & 351 exo & $311-379$ & 350 & 59.4 & 355 exo \\
\hline & $381-451$ & 432 & 20.9 & 448 exo & & & & \\
\hline & $451-525$ & 457 & 1.9 & 475 exo & $379-737$ & & & 637 exo \\
\hline & $\operatorname{Ash}\left(737^{\circ} \mathrm{C}\right)$ & & 0.8 & & Residue $\left(737^{\circ} \mathrm{C}\right)$ & & 11.4 & \\
\hline
\end{tabular}

a DTG peak temperature

$b$ mass loss percentage and ashresidue percentage in dry base

Three main stages can be distinguished during thermal decomposition of sisal fiber:

i) Evaporation of physically adsorbed water mainly occurs at temperatures below $100{ }^{\circ} \mathrm{C}$. The process represents a mass loss of $4-9 \%$ and is accompanied by an endothermic effect. In this range of temperature, an important decrease of crystallinity is observed in sisal (Fig. 2).

ii) Both with air and with nitrogen, two sub-stages are observed in the $200-400{ }^{\circ} \mathrm{C}$ range of thermal decomposition of sisal fiber.

ii.1) The first sub-stage, below $300{ }^{\circ} \mathrm{C}$, is attributed mainly to the degradation of non-cellulosic polysaccharides (NCP) of sisal, both of hemicellulose and pectins. Decomposition of sisal lignin also takes place, but in a lesser extent because of its low proportion. A mass loss of $17-21 \%$ is observed in this sub-stage for natural sisal, being slightly lower for washed sisal. The temperature at maximum mass loss rate, $\mathrm{Tb}_{\mathrm{NCP}}$, is around $280{ }^{\circ} \mathrm{C}$ for natural sisal and $294{ }^{\circ} \mathrm{C}$ for washed sisal, both in air and inert atmosphere, which are close to that of xylan decomposition, discussed in the previous section. The DTA plot obtained from washed sisal in nitrogen shows an exotherm with peak at $294{ }^{\circ} \mathrm{C}$, also observed in air at $293{ }^{\circ} \mathrm{C}$. This sub-stage coincides with the complete amorphization of the sisal cellulose, observed in Fig. 1B at temperatures above $290{ }^{\circ} \mathrm{C}$. The accomplished analysis presents a clear correspondence 
between DTA and thermogravimetric changes. The observed values are slightly different from those reported by Martin et al. [33], who described the maximum mass loss rate temperature at about $20{ }^{\circ} \mathrm{C}$ above the values found in this work.

ii.2) The second sub-stage, between 300 and $400{ }^{\circ} \mathrm{C}$ under nitrogen, corresponds almost exclusively to the degradation of cellulose by breaking of glycosidic linkages of the glucose chain. Pyrolysis of lignin also continues, although to a much lower extent. In air atmosphere, the combustion of NCP superimpose to the decomposition of sisal cellulose. This sub-stage shows a mass loss of almost $50 \%$ in the case of natural sisal, and about $60 \%$ for washed sisal. In air, $\mathrm{Tb}_{\mathrm{CEL}}$ is in the range from 336 to $339{ }^{\circ} \mathrm{C}$ for natural sisal and between 328 and $332{ }^{\circ} \mathrm{C}$ for washed sisal, while in nitrogen the differences shorten, falling in the range from 348 to $353{ }^{\circ} \mathrm{C}$. Martin et al. [33] reported the same trend for the raw and defatted sisal, but at temperatures 20 to $30^{\circ} \mathrm{C}$ higher than those found in this study. The degradation temperature of cellulose in sisal is slightly higher than that of pure cellulose, discussed in the previous section. It can be attributed to the protective effect of the rest of components present in sisal. The analysis in an inert atmosphere reveals that this step is accompanied by an endothermic effect, at about $355{ }^{\circ} \mathrm{C}$, due to the breaking of bonds, as it happens in the pure cellulose. However, in air an intense exotherm is observed at around 350 ${ }^{\circ} \mathrm{C}$, associated to the oxidation of the volatiles generated. But differently than cellulose, the endotherm preceding the exotherm is not observed. It is probably hidden by the exotherm resulting from combustion of sisal hemicellulose and other NCP.

It must be noted that the mass loss of the second sub-step is slightly higher in nitrogen atmosphere than in air (Table 2). The oxygen gain that saccharides undergo under oxidizing atmosphere can explain this difference, as Saikia concluded [32]. This phenomenon is also observed, even more pronounced, in biomass pure compounds.

iii) The third stage starts at $400{ }^{\circ} \mathrm{C}$. A small and sustained mass loss is observed in inert atmosphere, which corresponds to the process of carbonization. Very mild exothermic processes are observed in washed sisal, at around 650 and $635{ }^{\circ} \mathrm{C}$, with gas flows of 50 and $120 \mathrm{~mL} / \mathrm{min}$, respectively, but no substantial change in mass. The residue measured at $735{ }^{\circ} \mathrm{C}$ is lower for washed sisal (11\%) than for natural fiber $(20 \%)$.

In air, this stage corresponds to the combustion of the degraded material. It represents a mass loss of approximately $30 \%$ in the natural sisal and $21 \%$ in the washed sisal. The $\mathrm{Tb}_{\mathrm{COM}}$ ranges from 435 to 450 ${ }^{\circ} \mathrm{C}$, depending on the air flow rate. In the case of washed sisal, it changes from $442{ }^{\circ} \mathrm{C}$, with $50 \mathrm{~mL} / \mathrm{min}$ air flow, to $432{ }^{\circ} \mathrm{C}$, with a flow of $120 \mathrm{~mL} / \mathrm{min}$. The same applies to the exothermic peak temperature, which ranges from $457^{\circ} \mathrm{C}$ to $448{ }^{\circ} \mathrm{C}$. Sisal combustion is advanced with respect to that of pure cellulose. Thus, with a $120 \mathrm{~mL} / \mathrm{min}$ air flow, the $\mathrm{Tb}_{\mathrm{COM}}$ values of sisal and cellulose are $415{ }^{\circ} \mathrm{C}$ and $470{ }^{\circ} \mathrm{C}$, respectively. Comparing the peak temperatures of DTG and DTA signals along the combustion, exothermic effects appear delayed about 12 to $16^{\circ} \mathrm{C}$ with respect to the mass loss. A small lag of the heat flow signal in relation to that of mass loss is normal, because the heat is transferred through the crucibles before reaching the thermocouples. In this case, an extra delay is normal because the combustion probably takes place in the upper surface of the sample and thus, the sample itself is an additional barrier for the heat transfer. 
Thermal degradation of sisal lignin covers a wide range of temperatures as indicated by the thermal analysis of pure lignin. Since the proportion of this component is very low in the sisal fiber, its decomposition is not defined as clearly as in the case of the other components. The shoulder or tail that appears above $400^{\circ} \mathrm{C}$ on the DTG curve under inert atmosphere was associated with lignin [52,53]. Mass loss processes with relative maxima at 119, 168, 264, 367 (absolute maximum) and $418{ }^{\circ} \mathrm{C}$ were observed for Klason lignin extracted from sisal [33]. In our case, the DTA plot shows a small exothermic effect at around 410 to $435^{\circ} \mathrm{C}$, which is no longer detectable with a high flow of nitrogen.

In the analysis of the thermal decomposition of sisal fiber we must also take into account the analysis of the mineral content. Calcium represents the main component of sisal ashes, as it can be observed in the XRF results in Table 3, whose origin is mainly from calcium oxalate monohydrate, which is accumulated between ultimate fibers of sisal.

Table 3 XRF analysis of Natural and Washed Sisal ashes.

\begin{tabular}{lccc}
\hline & & Natural sisal & Washed sisal \\
\hline \% Soluble fraction & & 2 \\
\% Ash & & 1.2 & 0.3 \\
\% wt & $\mathrm{CaO}$ & 64.60 & 78.10 \\
& $\mathrm{MgO}$ & 10.51 & 14.82 \\
& $\mathrm{Na}_{2} \mathrm{O}$ & 5.92 & 0.76 \\
$\mathrm{SiO}_{2}$ & 4.77 & 1.56 \\
& $\mathrm{Fe}_{2} \mathrm{O}_{3}$ & 4.12 & 0.45 \\
$\mathrm{SO}_{3}$ & 3.00 & 1.49 \\
& $\mathrm{Al}_{2} \mathrm{O}_{3}$ & 2.68 & 0.73 \\
$\mathrm{P}_{2} \mathrm{O}_{5}$ & 1.85 & 0.84 \\
$\mathrm{~K}_{2} \mathrm{O}$ & 1.73 & 0.67 \\
$\mathrm{SrO}$ & 0.31 & 0.24 \\
& $\mathrm{TiO}$ & 0.18 & \\
& $\mathrm{MnO}$ & 0.13 & 0.13 \\
& $\mathrm{CuO}$ & 0.08 & 0.08 \\
$\mathrm{BaO}$ & 0.06 & \\
$\mathrm{ZnO}$ & 0.04 & 0.11 \\
$\mathrm{Cl}$ & 0.03 & 0.02 \\
\hline
\end{tabular}

However, due to the heterogeneity of natural fiber, the small proportion of this inorganic compound, and the superposition of the different degradation stages of natural fiber, not all the decomposition stages of this salt are perceptible,

1) $\mathrm{CaC}_{2} \mathrm{O}_{4} \cdot \mathrm{H}_{2} \mathrm{O} \rightarrow \mathrm{CaC}_{2} \mathrm{O}_{4}+\mathrm{H}_{2} \mathrm{O}$ (near $200^{\circ} \mathrm{C}$ )

2) $\mathrm{CaC}_{2} \mathrm{O}_{4} \rightarrow \mathrm{CaCO}_{3}+\mathrm{CO}$ (about $500^{\circ} \mathrm{C}$ )

3) $\mathrm{CaCO}_{3} \rightarrow \mathrm{CaO}+\mathrm{CO}_{2}$ (close to $800^{\circ} \mathrm{C}$ )

The first and third steps are endothermic, independently of the atmosphere. However, the second one is endothermic under inert atmosphere and exothermic in the presence of oxygen, due to immediate oxidation of the generated $\mathrm{CO}$ to $\mathrm{CO}_{2}$. Thus, just immediately after the combustion stage of sisal in air, the small exotherms accompanied by slight loss of mass in the range from 470 to $480{ }^{\circ} \mathrm{C}$ (Table 2), can 
be associated to the combined effect of oxalate decomposition and combustion of the resulting CO. It is likely that this effect is also contributed by the combustion of residual carbon originated from fiber lignin. On the other hand, degradation of natural sisal under nitrogen does not include any combustion step and thus, the mass loss associated to the oxalate-carbonate transformation can be clearly observed at $460{ }^{\circ} \mathrm{C}$.

A number of observations can be extracted from above results:

a. The energetic effects match better the mass loss under inert atmosphere than in air. In an oxidizing atmosphere the net exothermic effect is shifted to a higher temperature than its maximum rate of mass loss. The explanation lies in the combination of the various thermal effects caused by the different biomass components, prevailing exothermic volatilization of cellulose, the major component of sisal.

b. The oxidizing atmosphere promotes the pyrolysis stage to lower temperatures.

c. A higher flow rate of purge gas has little effect on the pyrolysis step, which produces a slight advancement of the decomposition temperature in air. In contrast, the increase of the flow rate exerts an important accelerating effect on the combustion stage. Both accelerating effects result from the fact that the presence of oxygen promotes oxidation reactions. The effect of the percentage of oxygen has been studied for the thermal decomposition of diverse lignocellulosic materials [54,55].

d. In comparison with pure cellulose, the temperature of the maximum mass loss rate of the decomposition stage of sisal cellulose, $\mathrm{Tb}_{\mathrm{CEL}}$, is slightly higher. It could be a consequence of an important stabilizing effect of PNC, as well as lignin, which is structurally mixed with cellulose and hemicellulose, as it was deduced for ethanol-extracted woods [56]. On the other hand, the temperature of the combustion stage, $\mathrm{Tb}_{\mathrm{COM}}$, is lower than that observed for pure cellulose. In an oxidizing atmosphere, combustion gasses (mainly $\mathrm{CO}_{2}$ and $\mathrm{H}_{2} \mathrm{O}$ ) from the lower thermal stability components could facilitate the oxidization of the carbonous residue of the cellulosic fraction of the sisal, thus advancing their combustion process.

\subsubsection{Effect of the hot-washing treatment on the thermal decomposition of sisal fiber}

From the previous analysis of the thermal behavior of natural and washed sisal, the effect of the washing treatment on the thermal decomposition can be summarized as follows:

a. Hot washing reduces the temperature range in which decomposition occurs. Furthermore, under inert atmosphere, a delay in the pyrolysis of the washed fiber is observed, both at the stage associated with NCP (approximately $13{ }^{\circ} \mathrm{C}$ higher in the washed fiber) and cellulose decomposition (between 2 to $4{ }^{\circ} \mathrm{C}$ in the washed fiber) (Table 2). These results agree with those found in other studies on washed lignocellulosic material $[9,57]$. Moreover, washed sisal presents the combustion stage slightly delayed with respect to the natural fiber (Fig. $\mathbf{4 b}$ ).

b. Washed sisal presents a higher mass loss rate during pyrolysis (Fig. 4a), while a higher combustion rate is observed with natural fiber (Fig. 4b).

c. Decomposition of NCP produces a slightly lower mass loss for washed sisal than for natural fiber, and the opposite occurs due to cellulose decomposition, as is visible in Fig. $\mathbf{4 a .}$ 
d. No effect of the type of atmosphere on the decomposition of the NCP was observed. However a clear effect was observed in the step associated with the cellulose, and even with a greater intensity, in the case of the washed fiber. The decomposition of sisal cellulose in air is anticipated with respect to pyrolysis under nitrogen, being more notorious in the case of washed fiber: about $20^{\circ} \mathrm{C}$ for washed sisal and $12{ }^{\circ} \mathrm{C}$ for natural sisal (Table 2).

e. The amount of char generated under inert atmosphere is lower in the washed sisal than in natural sisal

(Table 2).

f. The amount of residue obtained in air atmosphere is lower in the case of washed sisal. The washing process produces partial extraction of mineral substances, by partial solubilization. The proportions of $\mathrm{Ca}$ and $\mathrm{Mg}$ do not change significantly, whereas $\mathrm{Ti}, \mathrm{Ba}, \mathrm{Fe}$ and $\mathrm{Na}$ are entirely or almost entirely eliminated by the hot-washing process (Table 3).

Most of the aforementioned effects result from enriching the sample in cellulose as a consequence of the hot-washing removal of substances from the cell walls. The overall result is an increased thermal stability of NCP both in inert atmosphere and in air. The hot-washing process mostly extracts non-cellulosic components of low decomposition temperature, while the higher stability components remain in the fiber, thus increasing the $T b_{\mathrm{NCP}}$ values of the fiber. The slight increase of $T b_{\mathrm{CEL}}$ observed in washed sisal under inert atmosphere would result from a better reorganization and packing of the cellulose crystallites in the fibers, promoted by the removal of certain amount of cementitious material. The crystallinity index of washed sisal (69.7\%) and natural sisal (64.6\%) confirm that the washing process produces an increase of crystallinity, due to the elimination of cell components. On the other hand, an increase of cellulose thermal stability could also be attributed to the removal of inorganic salts, which could promote its degradation [6]. In contrast, in air, the oxidative pyrolysis hides this effect. The higher percentage of cellulose in washed sisal would explain both the acceleration of mass loss during the second pyrolysis sub-stage, and the delay of the combustion that occurs in an oxidizing atmosphere, getting slightly closer to the behavior of pure cellulose. It is known that the oxidative reactions are responsible for accelerating the depolymerization and mass loss rate of the cellulose decomposition in air [39]. This indicates that in the washed sisal oxidative reactions of cellulose are more favored than in natural fiber, as some protecting components were removed.

The lower percentage of carbon residue generated from washed sisal results from the removal of organic and inorganic matter. The removal of inorganic salts, which were analyzed by XRF, would also indirectly contribute to a lower amount of residue, since they could catalyze the formation of char $[58,59]$.

\subsection{FTIR analysis of gases evolved}

The three-dimensional diagrams of the infrared absorption spectra of the gases released under inert atmosphere from cellulose, xylan, lignin and hot- washed sisal are shown in Fig. 5. They indicate the evolution of gaseous products as a function of wavenumber and temperature. 


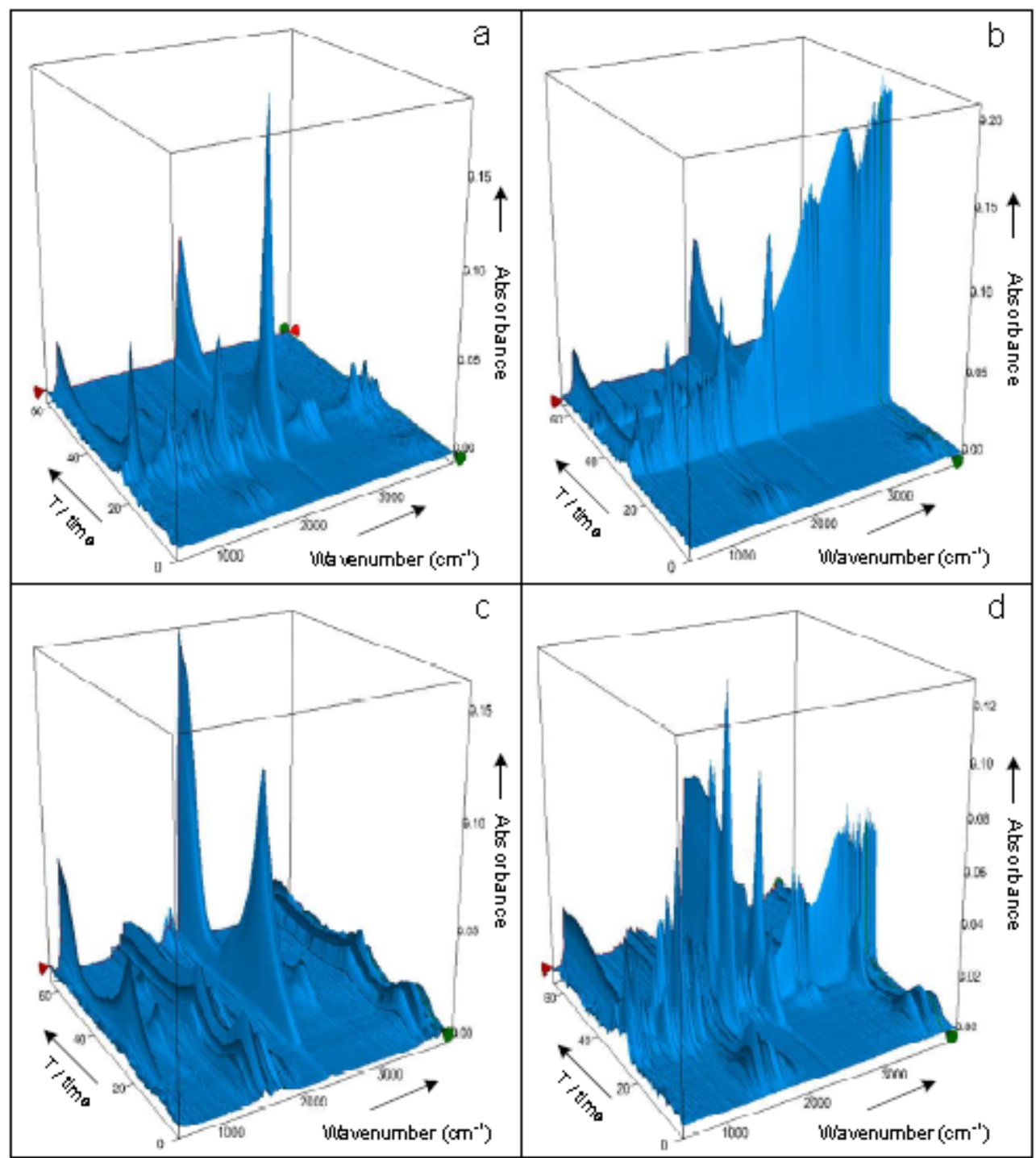

Figure 5. Three-dimensional FTIR spectra (Absorbance - wavenumber $-\mathrm{Z}$ (temperature, time)) of gases evolved under $120 \mathrm{~mL} / \mathrm{min}$ nitrogen purge, during decomposition of xylan (a), microcrystalline cellulose (b), lignin (c) and Washed Sisal (d).

The compounds identified in the evolved gases are listed subsequently, specifying the wavenumbers followed: $\mathrm{CO}_{2}\left(2359 \mathrm{~cm}^{-1}\right), \mathrm{CO}\left(2174 \mathrm{~cm}^{-1}\right), \mathrm{H}_{2} \mathrm{O}\left(3732 \mathrm{~cm}^{-1}\right), \mathrm{CH}_{4}\left(3015 \mathrm{~cm}^{-1}\right)$, acetic acid $\left(\mathrm{CH}_{3} \mathrm{C}(\mathrm{O}) \mathrm{OH}:\right.$ 1772, 1795 1273, 1178, 1070 and $\left.1003 \mathrm{~cm}^{-1}\right)$, formic acid $(\mathrm{HC}(\mathrm{O}) \mathrm{OH}: 1795,1772$, 1105 and $\left.1745 \mathrm{~cm}^{-1}\right)$, methanol $\left(\mathrm{CH}_{3} \mathrm{OH}: 1032 \mathrm{~cm}^{-1}\right)$, formaldehyde $(\mathrm{HC}(\mathrm{O}) \mathrm{H}: 2780$ [60], 1772, 1745 and $\left.1716 \mathrm{~cm}^{-1}\right)$ and some ketone, which tentatively can be assigned to 2-butanone $\left(\mathrm{CH}_{3} \mathrm{CH}_{2} \mathrm{C}(\mathrm{O}) \mathrm{CH}_{3}\right.$ : 1745,1734 and $1178 \mathrm{~cm}^{-1}$ ). Bold type is used to denote the characteristic IR peaks selected for substances monitoring, which were carefully chosen in such form that they correspond to a unique compound, avoiding the overlapping of different gaseous species. In case of coincidences, additional wavenumbers were used to analyze their evolution, which are indicated in italics.

Figure 6 shows the FTIR spectra of gases emitted by washed sisal fiber at two representative temperatures, $\mathrm{Tb}_{\mathrm{CEL}}$ and $\mathrm{Tb}_{\mathrm{NCP}}$, which respectively concern the decomposition of the non-cellulosic 
polysaccharides and cellulose. As in the case of microcrystalline cellulose, but to a lesser extent, it is observed a broad band at above $2500 \mathrm{~cm}^{-1}$, which after correction of the spectrum remains at around 3600-3000 $\mathrm{cm}^{-1}$, and a characteristic band at around $1047 \mathrm{~cm}^{-1}$, as indicated by the arrows in Fig. 6. These bands are attributed to a glycol type condensed phase, which was swept by the purge gas, as it will be discussed in the section of gases evolved from cellulose. Furthermore, differently than in the case of the pure biopolymers, a triplet band centered at $858 \mathrm{~cm}^{-1}$ is observed during the decomposition of sisal, denoted by an asterisk in Fig. 6, which is assigned to hydroxyacetaldehyde, $\left.(\mathrm{OH}) \mathrm{CH}_{2} \mathrm{C}(\mathrm{O}) \mathrm{H}\right)[60]$.

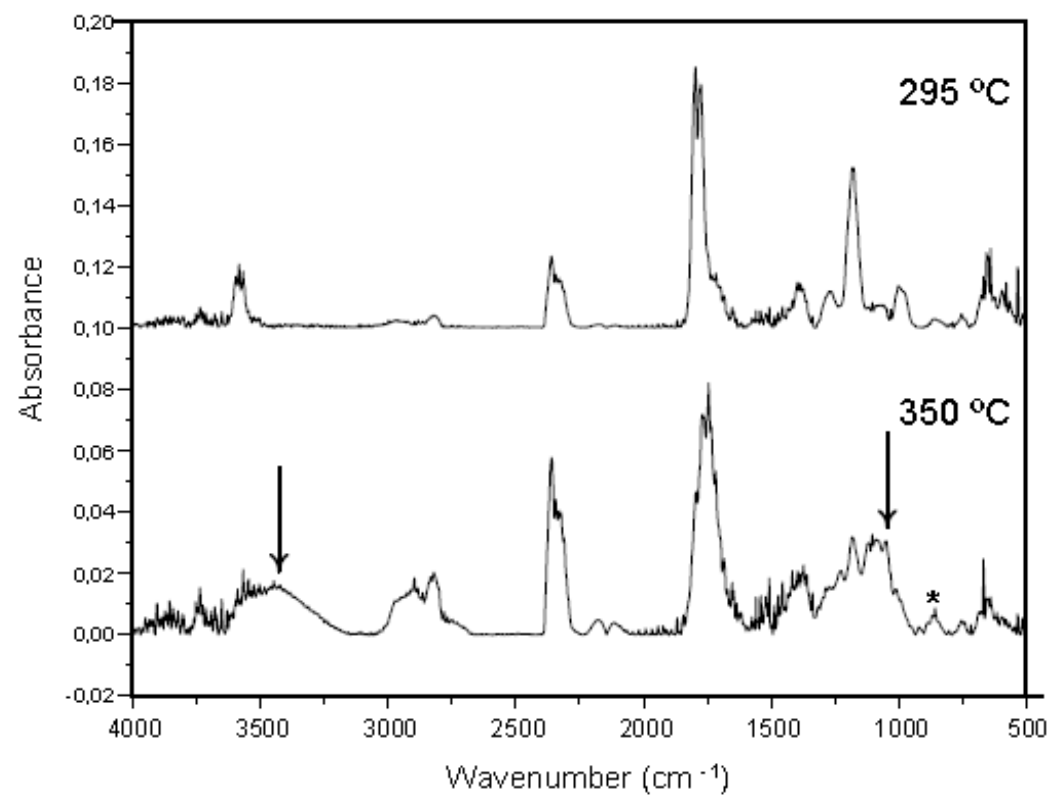

Figure 6. FTIR spectra of gases released out during decomposition of Washed Sisal under nitrogen atmosphere, at $\mathrm{Tb}_{\mathrm{PNC}}\left(295^{\circ} \mathrm{C}\right)$ and $\mathrm{Tb}_{\mathrm{CEL}}\left(350^{\circ} \mathrm{C}\right)$. Arrows denote characteristic bands of the emitted glycol phase, while the asterisk shows the vibration assigned to hydroxyacetaldehyde.

It is known that the absorbance at a specific wavenumber is linearly dependent on the concentration of gas, so the changes in absorbance reflect the tendency of concentration variation of the different gas species, provided that the FTIR procedures are the same [35,42].

Thermograms of Fig. 7, 8, 9 and 10 show the evolution of the main infrared bands associated with gaseous products for pure biomassic components and for washed sisal, which will be discussed in more detail in the following sections. Figure 11 shows the comparison of the evolution of these bands for the different components and the hot-washed sisal, under two flow rates of nitrogen, 50 and $120 \mathrm{~mL} / \mathrm{min}$. Data derived from the mentioned thermograms are collected in Tables $\mathbf{4}$ and $\mathbf{5}$, which show the relative intensities of different vibrations with respect to the maximum absorbance of $\mathrm{CO}_{2}$ emitted in the pyrolysis stage for each biocomponent and washed sisal. 
Table 4 Maximum intensities of the main infrared bands of volatiles emitted by biomass components, under $120 \mathrm{~mL} / \mathrm{min}$ of nitrogen or air purges, expressed as relative percentage respect to the maximum absorbance of $\mathrm{CO}_{2}$ evolved in the respective pyrolysis stages.

\begin{tabular}{|c|c|c|c|c|c|c|c|c|c|c|c|c|}
\hline & & $\begin{array}{c}\mathrm{CO} \\
\left(2174 \mathrm{~cm}^{-1}\right)\end{array}$ & $\begin{array}{c}\mathrm{H}_{2} \mathrm{O} \\
\left(3732 \mathrm{~cm}^{-1}\right)\end{array}$ & $\begin{array}{c}\mathrm{CH}_{4} \\
\left(3014 \mathrm{~cm}^{-1}\right)\end{array}$ & $\begin{array}{l}1035 \mathrm{~cm}^{-1} \\
\text { Methanol }\end{array}$ & $\begin{array}{l}1105 \mathrm{~cm}^{-1} \\
\text { Formic ac. }\end{array}$ & $\begin{array}{c}2780 \mathrm{~cm}^{-1} \\
\text { Formaldehyde }\end{array}$ & $\begin{array}{l}1178 \mathrm{~cm}^{-1} \\
\text { Acetic Ac. } \\
\text { Ketone }\end{array}$ & $\begin{array}{l}1734 \mathrm{~cm}^{-1} \\
\text { Ketone }\end{array}$ & $\begin{array}{l}1772 \mathrm{~cm}^{-1} \\
\text { Acetic Ac. } \\
\text { Formaldehyde } \\
\text { Formic Ac. }\end{array}$ & $\begin{array}{l}1795 \mathrm{~cm}^{-1} \\
\text { Acetic Ac. } \\
\text { Formic Ac. }\end{array}$ & $\begin{array}{c}1047 \mathrm{~cm}^{-1} \\
\text { Glycol }\end{array}$ \\
\hline \multirow{2}{*}{ Cellulose } & $\mathrm{N}_{2}$ & 6.0 & 40.3 & 4.2 & $a$ & $55.6^{b}$ & 17.8 & $38.2^{c}$ & 107 & $62.8^{c}$ & $47.6^{c}$ & 105 \\
\hline & Air & 4.8 & 13.1 & N.D. & $a$ & $5.7^{b}$ & 2.7 & $2.1^{c}$ & 22.8 & $16.5^{c}$ & $16.2^{c}$ & 9.2 \\
\hline \multirow{2}{*}{ Xylan } & $\mathrm{N}_{2}$ & 11.5 & 10.2 & 5.6 & 9.3 & 13.8 & 0.9 & $4.2 / 6.4$ & 33.4 & $9.9 / 26.9$ & $9.9 / 23.9$ & N.D. \\
\hline & Air & 5.7 & 13.4 & N.D. & 9.1 & 13.7 & 1.6 & $1.9 / 6.9$ & 26.3 & $3.2 / 24.0$ & $3.5 / 20.5$ & N.D. \\
\hline Lignin & $\mathrm{N}_{2}$ & 2.2 & 15.4 & $11.7 / 18.8$ & 14.0 & N.D. & N.D. & N.D. & $d$ & $d$ & $d$ & N.D. \\
\hline
\end{tabular}

\footnotetext{
/ Two stages can be distinguishes

N.D. Vibration no detected

a if vibration exists is hidden by the glycol band

Its intensity is increased due to the glycol band

acetic acid contribution doesn't exist

$d \quad$ only water vibrations are observable
}

Table 5 Maximun intensities of the main infrared bands of volatiles emitted by Washed Sisal, under different atmosphere and flow rate, expressed as relative percentage respect to the maximum absorbance of $\mathrm{CO}_{2}$ evolved in the respective pyrolysis stages.

\begin{tabular}{|c|c|c|c|c|c|c|c|c|c|c|c|c|}
\hline Washed Sisal & $\begin{array}{c}\mathrm{CO}_{2} \\
\left(2359 \mathrm{~cm}^{-1}\right)\end{array}$ & $\begin{array}{c}\mathrm{CO} \\
\left(2174 \mathrm{~cm}^{-1}\right)\end{array}$ & $\begin{array}{c}\mathrm{H}_{2} \mathrm{O} \\
\left(3732 \mathrm{~cm}^{-1}\right)\end{array}$ & $\begin{array}{c}\mathrm{CH}_{4} \\
\left(3014 \mathrm{~cm}^{-1}\right)\end{array}$ & $\begin{array}{l}1035 \mathrm{~cm}^{-1} \\
\text { Methanol }\end{array}$ & $\begin{array}{l}1105 \mathrm{~cm}^{-1} \\
\text { Formic ac. }\end{array}$ & $\begin{array}{c}2780 \mathrm{~cm}^{-1} \\
\text { Formaldehyde }\end{array}$ & $\begin{array}{l}1178 \mathrm{~cm}^{-1} \\
\text { Acetic Ac. } \\
\text { Ketone }\end{array}$ & $\begin{array}{l}1734 \mathrm{~cm}^{-1} \\
\text { Ketone }\end{array}$ & $\begin{array}{c}1772 \mathrm{~cm}^{-1} \\
\text { Acetic Ac. } \\
\text { Formaldehyde } \\
\text { Formic Ac. }\end{array}$ & $\begin{array}{l}1795 \mathrm{~cm}^{-1} \\
\text { Acetic Ac. } \\
\text { Formic Ac. }\end{array}$ & $\begin{array}{l}1047 \mathrm{~cm}^{-1} \\
\text { Glycol }\end{array}$ \\
\hline \multirow{2}{*}{$50 \mathrm{~mL} / \mathrm{min}$} & $42.0 / 100$ & 1.8 / 8.9 & 7.7 / 19.1 & $5.1 / 5.3$ & $11.4 / 22.2^{a}$ & $11.3 / 39.0^{a}$ & $1.4 / 12.4$ & $84.8 / 48.6$ & $27.0 / 94.3$ & $139 / 111$ & $160 / 81.5$ & $9.5^{b} / 36.3$ \\
\hline & $18.8 / 100$ & $0.9 / 4.5$ & $1.7 / 9.8$ & N.D. & $2.8 / 3.6^{a}$ & $2.7 / 5.4^{a}$ & N.D. / 2.0 & $17.7 / 11.3$ & $1.3 / 12.6$ & $27.6 / 24.3$ & $33.4 / 24.0$ & $2.3^{b} / 4.6$ \\
\hline \multirow{2}{*}{$120 \mathrm{~mL} / \mathrm{min}{ }_{\text {Air }}^{\mathrm{N}_{2}}$} & $40.0 / 100$ & 1.6 / 8.4 & $7.9 / 17.1$ & $5.5 / 5.9$ & $10.7 / 32.5^{a}$ & $13.9 / 56.6^{a}$ & $1.3 / 13.1$ & $92.2 / 54.5$ & $29.5 / 117$ & $138 / 121$ & $160 / 79.3$ & $9.1^{b} / 50.8$ \\
\hline & $26.5 / 100$ & $0.7 / 3.9$ & $3.6 / 14.2$ & N.D. & $1.9 / 4.0^{a}$ & $2.3 / 6.7^{a}$ & $0.2 / 2.1$ & $15.4 / 9.5$ & $7.0 / 28.9$ & $24.3 / 30.0$ & $27.0 / 23.3$ & $1.6^{b} / 6.0$ \\
\hline
\end{tabular}

/ NCP and cellulose stages are distinguished ND Vibration is not detected

$a$ Its intensity is increased due to the glycol band

$b$ Overlapping with Acetic acid band 


\subsubsection{Analysis of gases evolved from the pure lignocellulosic components}

The analysis of gases evolved in the decomposition of pure components in air and nitrogen is described, previously to study the more complex case of sisal fiber.

\section{i) Xylan:}

In nitrogen atmosphere, the following species are detected at temperatures below $350^{\circ} \mathrm{C}: \mathrm{CO}_{2}$, $\mathrm{CO}, \mathrm{H}_{2} \mathrm{O}$, acetic acid, formic acid, methanol, formaldehyde and a ketone, with vibrations near 1178 and $1734 \mathrm{~cm}^{-1}$ (Fig. 7).
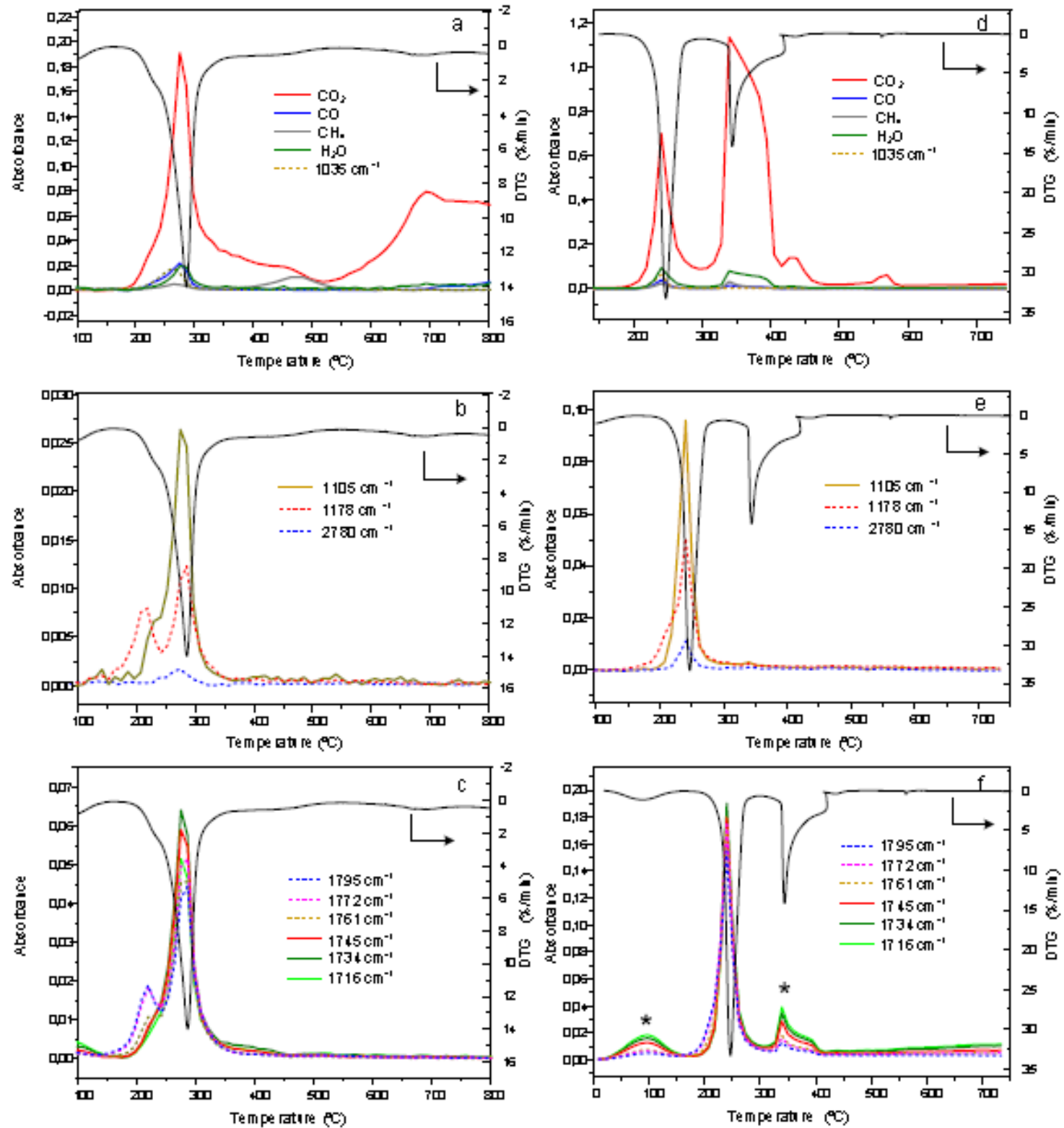

Figure 7. Evolution of the main infrared bands of the volatiles emitted during xylan decomposition, under $120 \mathrm{~mL} / \mathrm{min}$ nitrogen (a-c) and air (d-f) purges, with the corresponding DTG curve.

Among the three biomass components considered, xylan is the one which presents the highest absorbance of $\mathrm{CO}_{2}$ and the highest $\mathrm{CO} / \mathrm{CO}_{2}$ ratio (Table 4). $\mathrm{CO}_{2}$ comes from the breakdown of $\mathrm{C}=\mathrm{O}$ and $\mathrm{COOH}$ groups [42]. It would mainly come from decarboxylation reactions of O-acetyl units according to 
Shen et al. [61]. In the present case that contribution must be less important, since the starting material is a hemicellulose mostly composed of xylose units. The CO formation is attributed to decarbonylation reactions, specifically to the breakdown of $\mathrm{COC}$ and $\mathrm{C}=\mathrm{O}$ [42], due to the decomposition of the ringopened intermediate products [61]. The $\mathrm{H}_{2} \mathrm{O}$ emission during the pyrolysis stage is mainly derived from the hydroxyl groups of xylopyranose units. The emission of acetic acid and methanol is attributed to the breakdown of the O-acetyl and O-methyl groups of the residual side chains, which are even present after the extraction and purification of commercial xylan. The presence of various ketones in the products resulting from xylan pyrolysis was identified using Py-GC/MS by Y. Wu et al. [62], who found at $260{ }^{\circ} \mathrm{C}$ mainly 1-hydroxy-2-butanone, 1-hydroxy-propanone, and, to a lesser extent, 4-hydroxy-3-hexanone.

In nitrogen at temperatures above $400{ }^{\circ} \mathrm{C}$ certain gases generated by secondary reactions of decomposition of anhydrous sugars are distinguished. Thus, the $\mathrm{CO}_{2}$ emission continues, but slightly, and $\mathrm{CH}_{4}$ is detected with a maximum near $470{ }^{\circ} \mathrm{C}$, close to the exothermic effect observed in the DTA of xylan (Table 1). $\mathrm{CH}_{4}$ is formed by breaking $\mathrm{R}-\mathrm{CH}_{3}$ bonds, which requires elevated temperatures due to its high stability [61]. The $\mathrm{CO}_{2}$ emission starts to increase at $550{ }^{\circ} \mathrm{C}$, reaching a maximum rate at about $700{ }^{\circ} \mathrm{C}$, temperature at which a new $\mathrm{CO}$ emission begins.

During the pyrolytic decomposition stage in air the same gases are detected than when using inert atmosphere. Their proportions with respect to the $\mathrm{CO}_{2}$ emitted are quite similar to those obtained under nitrogen atmosphere, with the exception of CO principally, whose emission diminishes in air (Table 4). Furthermore, mass losses in air and nitrogen are similar, 59 and 63\% respectively (Table 1). It can be explained through the phenomena that affect the volatiles emitted in the decomposition step. In this case, the decomposition temperature of xylan (about $290^{\circ} \mathrm{C}$ ) is sufficiently low so that, firstly, most of the volatiles generated are not oxidized to $\mathrm{CO}$ or $\mathrm{CO}_{2}$ in air, and on the other hand, the self-generated $\mathrm{CO}$ would oxidize to $\mathrm{CO}_{2}$ in contact with air through the thermodynamically favored reaction: $2 \mathrm{CO}+\mathrm{O}_{2}$ $\rightarrow 2 \mathrm{CO}_{2}$, which explains the lower proportion of $\mathrm{CO}$. The $\mathrm{CO}_{2}$ emission during the combustion process, between $300-420^{\circ} \mathrm{C}$, is intense and presents an asymmetrical shape which indicates that the process is triggered by the temperature once the energy barrier of the combustion process is reached. Then, the combustion rate decreases as the remaining amount of sample decreases. The corresponding DTG plot reflects the same process, but the DTG peak is more resolved due to the delay and mixing of components that may occur during the gas flow from the TGA furnace to the FTIR detector [63]. Additionally, small emissions of $\mathrm{CO}_{2}, \mathrm{H}_{2} \mathrm{O}$ and $\mathrm{CO}$, associated with mild exothermic effects are observed at around $440{ }^{\circ} \mathrm{C}$ and at $570{ }^{\circ} \mathrm{C}$ (Fig. 7D and Table 4). The exotherm at $440{ }^{\circ} \mathrm{C}$ corresponds to the completion of the $300-$ $420^{\circ} \mathrm{C}$ combustion process, which produced an overheating on the programmed ramp. Then, the process was halted as the temperature decreased to recover the programmed values, as it can be observed on the DTG plot. The exotherm at $570{ }^{\circ} \mathrm{C}$ corresponds to combustion of a more stable carbon residue, which resulted from degradation of the most stable structures.

\section{ii) Cellulose:}

In nitrogen, at temperatures below $400{ }^{\circ} \mathrm{C}, \mathrm{CO}_{2}, \mathrm{CO}, \mathrm{H}_{2} \mathrm{O}$, formaldehyde, formic acid, and 2butanone are detected, besides a glycol condensate (Fig. 8). This condensate is assigned to 1,2- 
propanediol, intermediate reaction product, and to ethylene glycol, which was observed in pyrolytic decomposition of cellulose [64,65]. It should be noted that the signal of formic acid $\left(1105 \mathrm{~cm}^{-1}\right)$ is increased due to the glycol $\left(1047 \mathrm{~cm}^{-1}\right.$, Fig. 8B and 11C), which also hides methanol $\left(1032 \mathrm{~cm}^{-1}\right)$. Thus, it is not possible to determine the proportion of each component (Fig. 8A and 11F, and Table 4).
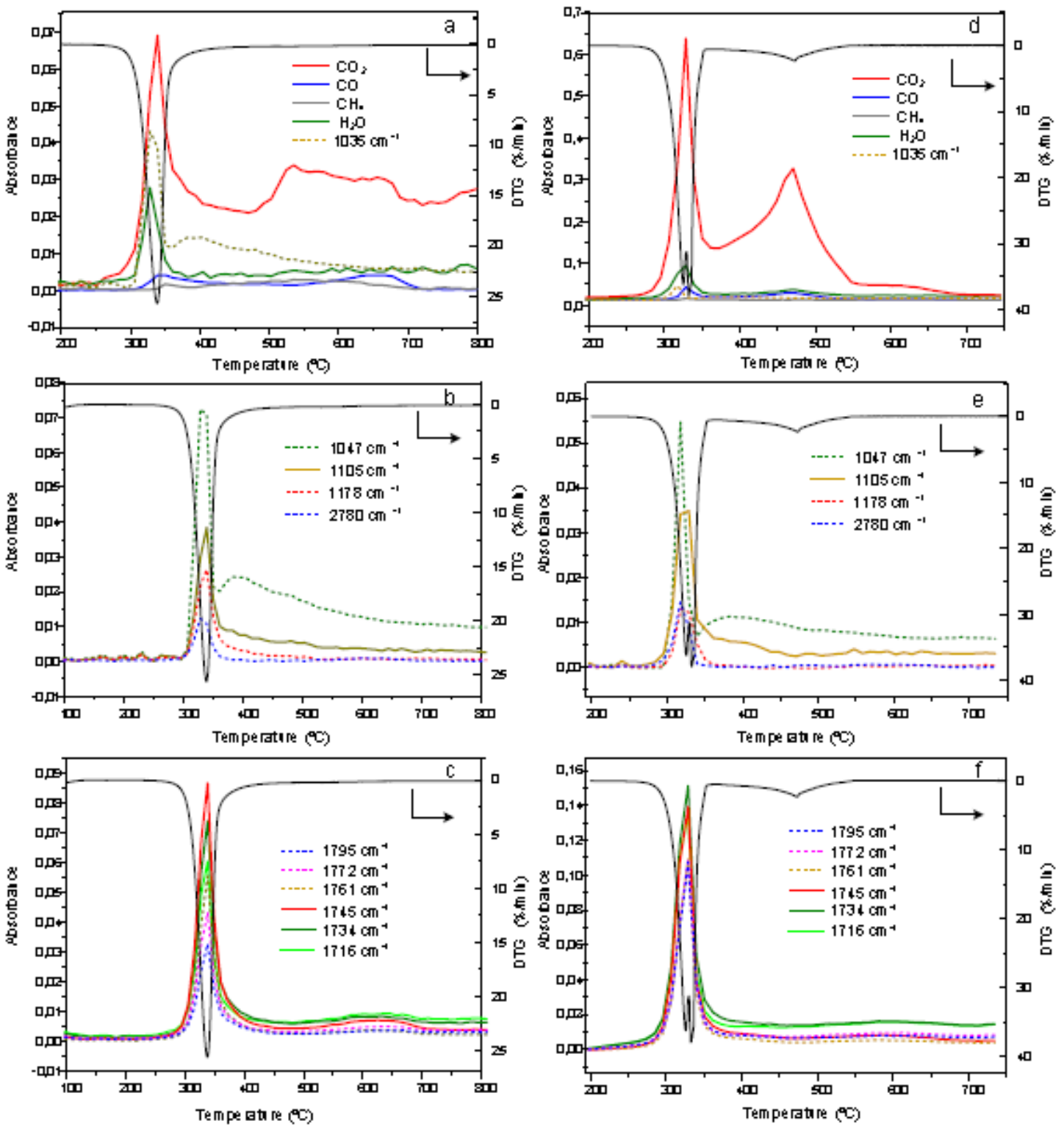

Figure 8. Evolution of the main infrared bands of the volatiles emitted during microcrystalline cellulose decomposition, under $120 \mathrm{~mL} / \mathrm{min}$ nitrogen (a-c) and air (d-f) purges, with the corresponding DTG curve.

In contrast to xylan most of the main gaseous products of cellulose are evolved together, in a narrower range of temperatures, with maximum close to $330-340{ }^{\circ} \mathrm{C}$, except for $\mathrm{CH}_{4}$, which is emitted at higher temperature. Cellulose is the component that produces the highest emissions of $\mathrm{H}_{2} \mathrm{O}$ and organic products with respect to the $\mathrm{CO}_{2}$ emitted (Table 4). The breaking of the glycosidic linkages and ring opening generate liquid and gaseous intermediates, whose identity and proportion are dependent on the pyrolysis conditions. Shafizadeh [66] and subsequently Shen et al. [67] collected and proposed different routes of formation of $\mathrm{CO}_{2}, \mathrm{CO}, \mathrm{CH}_{4}$, formaldehyde, methanol and acetic acid, among other products of 
decomposition of cellulose. In our study acetic acid has not been detected, so the bands located at 1178, 1772 and $1795 \mathrm{~cm}^{-1}$, shown in Fig. 8B, 8C, 11G, 11H and 11L are associated to acetone, formaldehyde and formic acid. Shen et al. [67] indicate that the formation of CO is favored by high temperatures and long residence times, which explain that $\mathrm{CO}$ formation is mainly affected by the secondary reactions, especially of aldehyde-type low molecular weight compounds. Nevertheless, $\mathrm{CO}_{2}$ is mainly formed in the early stages of the pyrolysis of cellulose. Li et al. [60] found that formaldehyde formation is favored by a lower purge flow and by longer residence times, which would explain its formation through secondary reactions. They explain that at high temperatures, near $550{ }^{\circ} \mathrm{C}$, formaldehyde decomposes to generate $\mathrm{CO}$ and $\mathrm{H}_{2}$, which is consistent with the observation of Shen et al. Various ketones have been proposed and detected at the primary decomposition and pyrolysis of cellulose. Thus, 2,3-butanedione is among the products of pyrolysis of levoglucosan, a major decomposition product of cellulose [68]. 2-butanone, detected here at temperatures below $400{ }^{\circ} \mathrm{C}$, has also been detected by Py-GC/MS analysis [62]. According to other reports, it may come from decarboxylation of levulinic acid [66]. Radlein et al. [69] found formic acid in the pyrolysis products of different celluloses, which would be originated from the decomposition of levoglucosan according to Hosoya et al. [70].

In nitrogen, at temperatures above $450^{\circ} \mathrm{C}, \mathrm{CO}_{2}, \mathrm{CO}$ and $\mathrm{CH}_{4}$ are detected, resulting from side reactions. In this stage, maximum emission of $\mathrm{CO}_{2}$ and $\mathrm{CH}_{4}$ is observed at about $530{ }^{\circ} \mathrm{C}$, while the maxima of $\mathrm{CO}_{2}$ and $\mathrm{CO}$ appear at $650^{\circ} \mathrm{C}$, as shown in Fig. 8A, 11A, 11E and 11I.

The products detected during the decomposition in air of cellulose are the same than under inert atmosphere. However, compared to that of $\mathrm{CO}_{2}$, the emission of organic compounds and $\mathrm{H}_{2} \mathrm{O}$ has decreased significantly in air, while the proportion of $\mathrm{CO}$ is maintained in almost the same proportion as in nitrogen (Table 4). Since the mass loss after pyrolysis under air and nitrogen are similar, the explanation lies primarily in the changes suffered by the emitted gaseous compound.

In an oxidizing atmosphere, when the temperature is high enough, it could happen that at the same instant in which the decomposition/pyrolysis of the cellulose occurs, the volatile organics generated oxidize, which would be favored by the presence of steam. Thus, a gasification reaction explains the lower proportion of $\mathrm{H}_{2} \mathrm{O}$ detected. On the other hand, the consumption of $\mathrm{CO}$ according to the reaction $2 \mathrm{CO}+\mathrm{O}_{2} \rightarrow 2 \mathrm{CO}_{2}$ is less thermodynamically favored, which explains its higher relative proportion under air atmosphere. The evolution of $\mathrm{CO}_{2}$ in the combustion process comprises a wide interval of temperatures, from 370 to $700{ }^{\circ} \mathrm{C}$ and maximum at $470{ }^{\circ} \mathrm{C}$, where $\mathrm{CO}$ and $\mathrm{H}_{2} \mathrm{O}$ are detected. Exothermic effects, around 540 and $600{ }^{\circ} \mathrm{C}$, detected in the DTA of the cellulose, correspond mainly to the emission of $\mathrm{CO}_{2}$, as observed in Fig. 8B, associated to additional combustion phenomena.

\section{iii) Lignin:}

Unlike cellulose and hemicellulose, degradation of lignin under inert atmosphere covers a very wide range of temperature, from 130 to $500{ }^{\circ} \mathrm{C}$ (Fig. 9). The gases detected in this interval are $\mathrm{CO}_{2}, \mathrm{CO}$, $\mathrm{H}_{2} \mathrm{O}, \mathrm{CH}_{4}$ and $\mathrm{CH}_{3} \mathrm{OH}$. No other organic compounds were detected. 

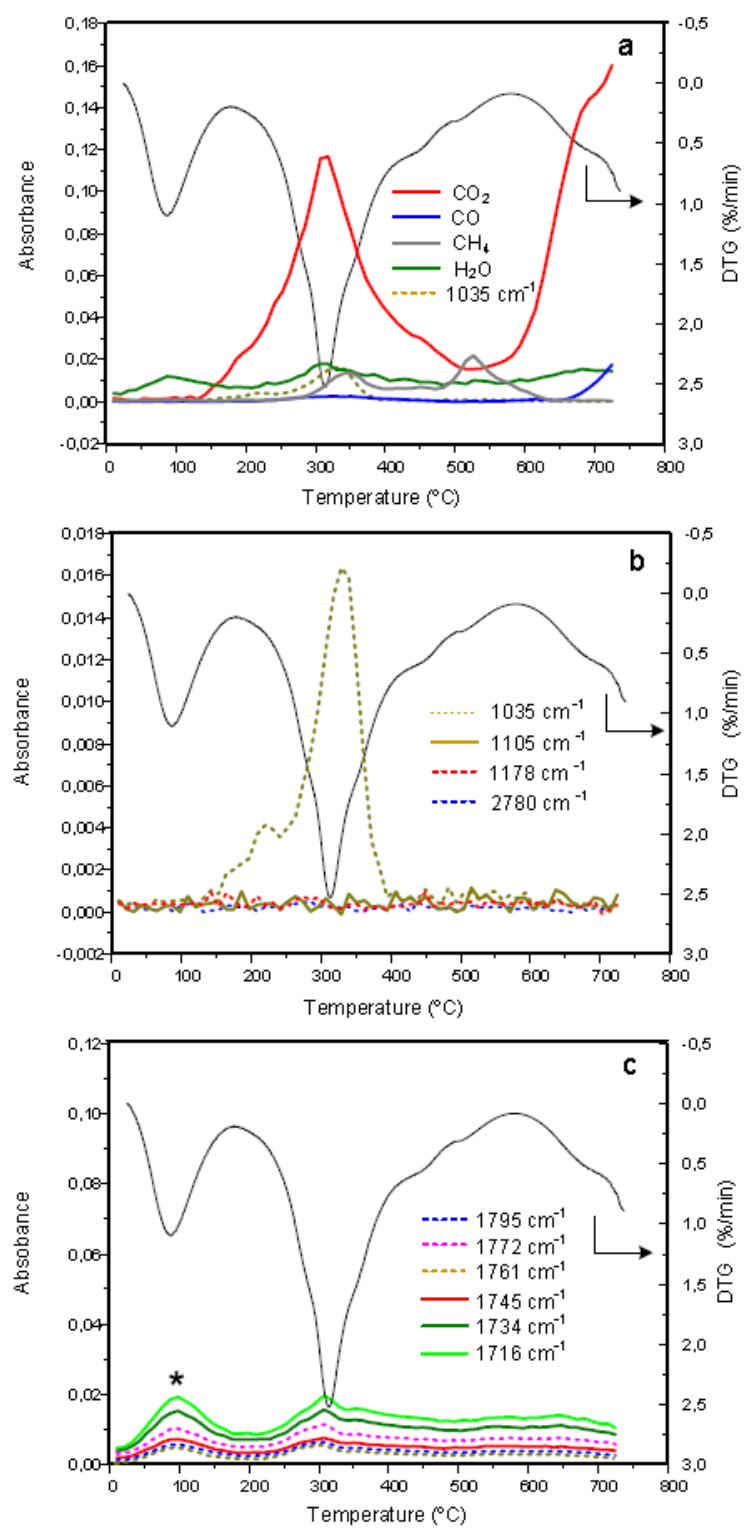

Figure 9. Evolution of the main infrared bands of the volatiles emitted during lignin decomposition under $120 \mathrm{~mL} / \mathrm{min}$ nitrogen purge, with the corresponding DTG curve.

Of the three biomass components, lignin is the one which produces the highest proportion of $\mathrm{CH}_{4}$ and $\mathrm{CH}_{3} \mathrm{OH}$ and the lowest of $\mathrm{CO}$ with respect to the maximum absorbance of $\mathrm{CO}_{2}$ emitted at the pyrolysis stage (Table 4). At temperatures below $500{ }^{\circ} \mathrm{C}$, the emission of $\mathrm{H}_{2} \mathrm{O}$ can be associated to aliphatic and aromatic hydroxyl groups, and the emission of $\mathrm{CO}_{2}$ and $\mathrm{CO}$ to cracking and reforming of the carboxyl, carbonyl and ester groups, present in the side chains of the phenylpropane units [41]. Their evolution above $500{ }^{\circ} \mathrm{C}$ is associated with the secondary pyrolysis of volatiles. In particular, several authors claim that $\mathrm{CO}$ is originated at the breaking of two different types of ether bonds: at low temperature the ether bonds between different lignin subunits, whilst at high temperature diaryl ether groups are involved [71,72]. Below $400^{\circ} \mathrm{C}$, the evolution of $\mathrm{CH}_{3} \mathrm{OH}$ and $\mathrm{CH}_{4}$ is mainly associated with the cleavage and demethylation of methoxyl groups $\left(-\mathrm{O}-\mathrm{CH}_{3}\right)$ present in lignin [42,73]. Methanol 
formation may also be contributed by the $-\mathrm{CH}_{2} \mathrm{OH}$ groups located on the $\gamma$ carbon of the alkyl lateral chain of the phenylpropane units $[41,71]$. Above $400^{\circ} \mathrm{C}$ methane emission continues, reaching a second maximum at $525^{\circ} \mathrm{C}$, more intense than the first one. It is produced by side reactions, and also by primary reactions of condensation and reorganization of the char. At these high temperatures the rupture of the aromatic rings starts, generating methyl radicals and methylene groups, and finally forming methane [41] [71]. From $600{ }^{\circ} \mathrm{C}$ methane signal begins to disappear, because it breaks down into $\mathrm{H}_{2}$ and $\mathrm{C}$ [72].

The composition and evolution of gases emitted by lignin in this study turn out to be virtually identical to those of alkaline lignin studied by Yang et al. [42]. Other studies describe the emission of other organic compounds, not detected in the present work, such as formaldehyde, formic acid and phenols originated by the rupture of phenylpropane units. The type of lignin and the extraction method would explain the differences in the composition of the emitted gases. The basic reason why a smaller variety of volatile organic compounds is detected is that char formation reactions are favored against the generation of volatile compounds. G type lignins, as the one used in this study are prone to undergo condensation and coupling reactions between phenylpropane units, causing them to generate more amount of char and emit less amount of phenolic derivatives [41], which would be characterized by intense vibrations around 1500, 1250 and $1100 \mathrm{~cm}^{-1}$ [73]. On the other hand, lignins containing little sulfur, as the one studied, are more affected by this type of condensation reactions. Fenner and Lephardt [73] indicate that the incorporation of sulfur facilitates the fragmentation of phenylpropane units and decreases its condensation.

\subsubsection{Analysis of the gases emitted by hot-washed sisal fiber}

The evolution with temperature of the main infrared bands of the gases emitted during the decomposition under inert and oxidant atmosphere of washed sisal fibers is shown in Fig. 10. The gaseous components observed at different stages are summarized below:

i) At temperatures below $150{ }^{\circ} \mathrm{C}, \mathrm{H}_{2} \mathrm{O}$ emission is mainly from to the moisture in the fibers.

ii) In the first sub-step, below $300{ }^{\circ} \mathrm{C}$, the gases $\mathrm{CO}, \mathrm{CO}_{2}$ and $\mathrm{H}_{2} \mathrm{O}$ come from the decomposition of sisal lignin and mainly from hemicelluloses and other NCP still present in the washed sisal. The emission of acetic acid, formic acid, methanol, formaldehyde, and some ketone, which may be tentatively assigned to 2-butanone, is mainly due to decomposition of hemicellulose. Sisal lignin should also contribute to the emission of methanol and acetic acid as suggested by other studies with HGS type lignins [41]. Nevertheless, in studies with wood, the emission of formic acid at this stage has been associated only with the hemicellulose and not with lignin [74]. Notably, the proportion of acetic acid emitted (Table 5) is proportionally much higher than that observed in the pure xylan (Table 4). This is because sisal hemicelluloses contain more side chains with acetyl groups than the xylan studied. 

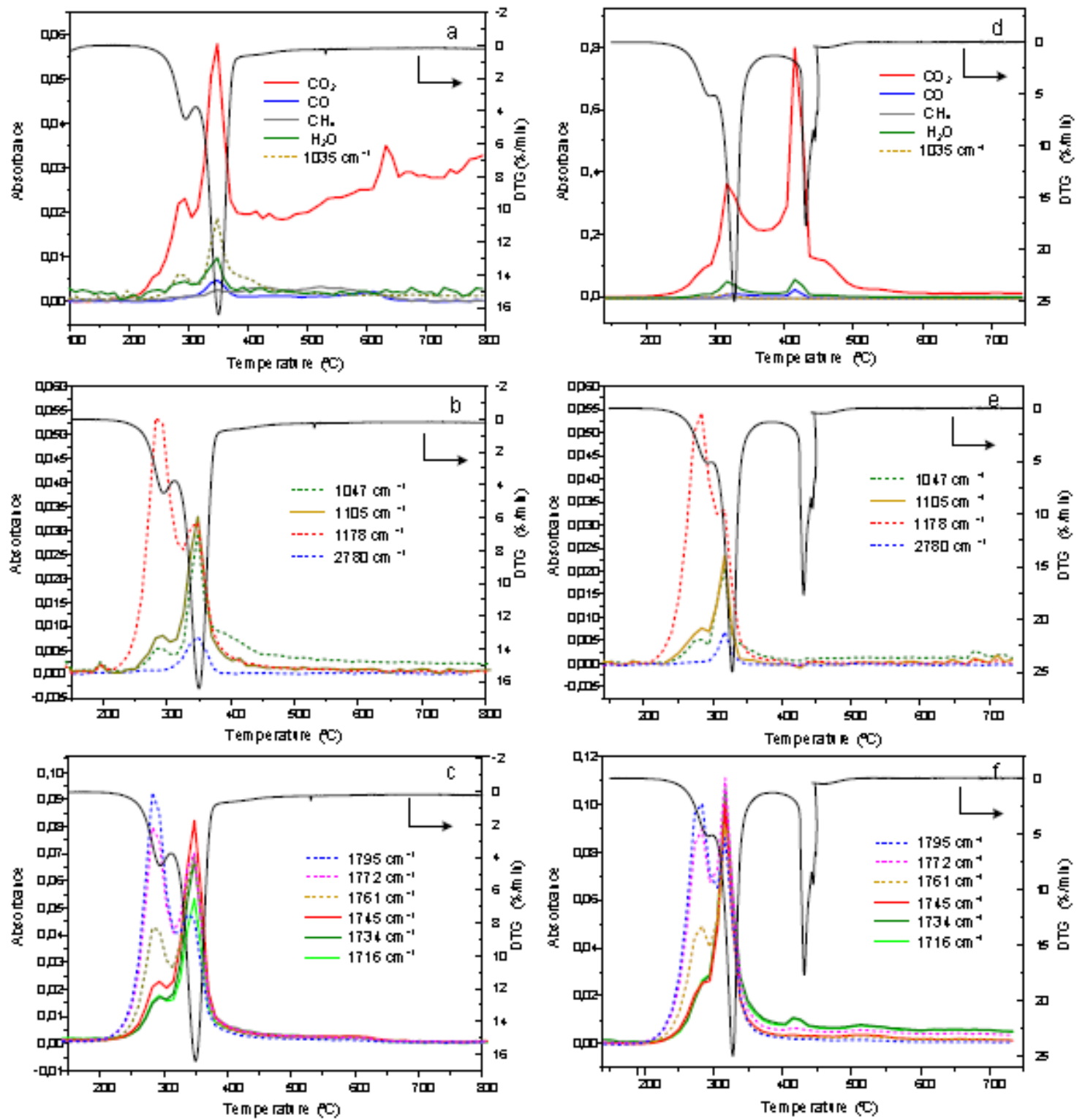

Figure 10. Evolution of the main infrared bands of the volatiles emitted during microcrystalline cellulose decomposition, under $120 \mathrm{~mL} / \mathrm{min}$ nitrogen (a-c) and air (d-f) purges, with the corresponding DTG curve.

In the second sub-stage, between 300 and $400{ }^{\circ} \mathrm{C}$, the emitted compounds are mainly due to the pyrolysis of sisal cellulose: $\mathrm{CO}, \mathrm{CO}_{2}, \mathrm{H}_{2} \mathrm{O}$, glycol, formaldehyde, methanol, formic acid and ketone, assigned tentatively to 2-butanone, as well as hydroxyacetaldehyde which starts to be generated in the previous stage. The latter compound may appear as a product of decomposition of cellulose by a competitive route to the formation of levoglucosan, the main component of cellulose tar [60,67]. The low amount of hydroxyacetaldehyde emitted during the pyrolysis of sisal cellulose suggests a route of decomposition different from that of the microcrystalline cellulose studied in this work, in which this compound was not observed. The maximum emissions of all these compounds match with the maximum mass loss rate, as shown in Fig. 10. Acetic acid bands decrease very quickly at the end of the first substage. Thus, the vibrations of the carbonyl groups that remain in the second sub-step can be only assigned to formaldehyde, formic and 2-butanone (Fig. 10C). To a lesser extent sisal lignin contribute to the 
emission of $\mathrm{CO}, \mathrm{CO}_{2}$ and $\mathrm{H}_{2} \mathrm{O}$, and probably also to methanol, formic acid and acetic acid. The emission of $\mathrm{CH}_{4}$ in nitrogen starts at around $360^{\circ} \mathrm{C}$ (Fig. 10A and 11I). It is mainly associated with the rupture of the methoxyl groups of lignin, but its signal is weak, being obscured by the C-H stretching vibrations of other organic compounds. Additionally, at the end of this sub-stage in air, the combustion of sisal hemicellulose and other NCP occurs, emitting $\mathrm{CO}_{2}$ and $\mathrm{H}_{2} \mathrm{O}$ (Fig. 10D).
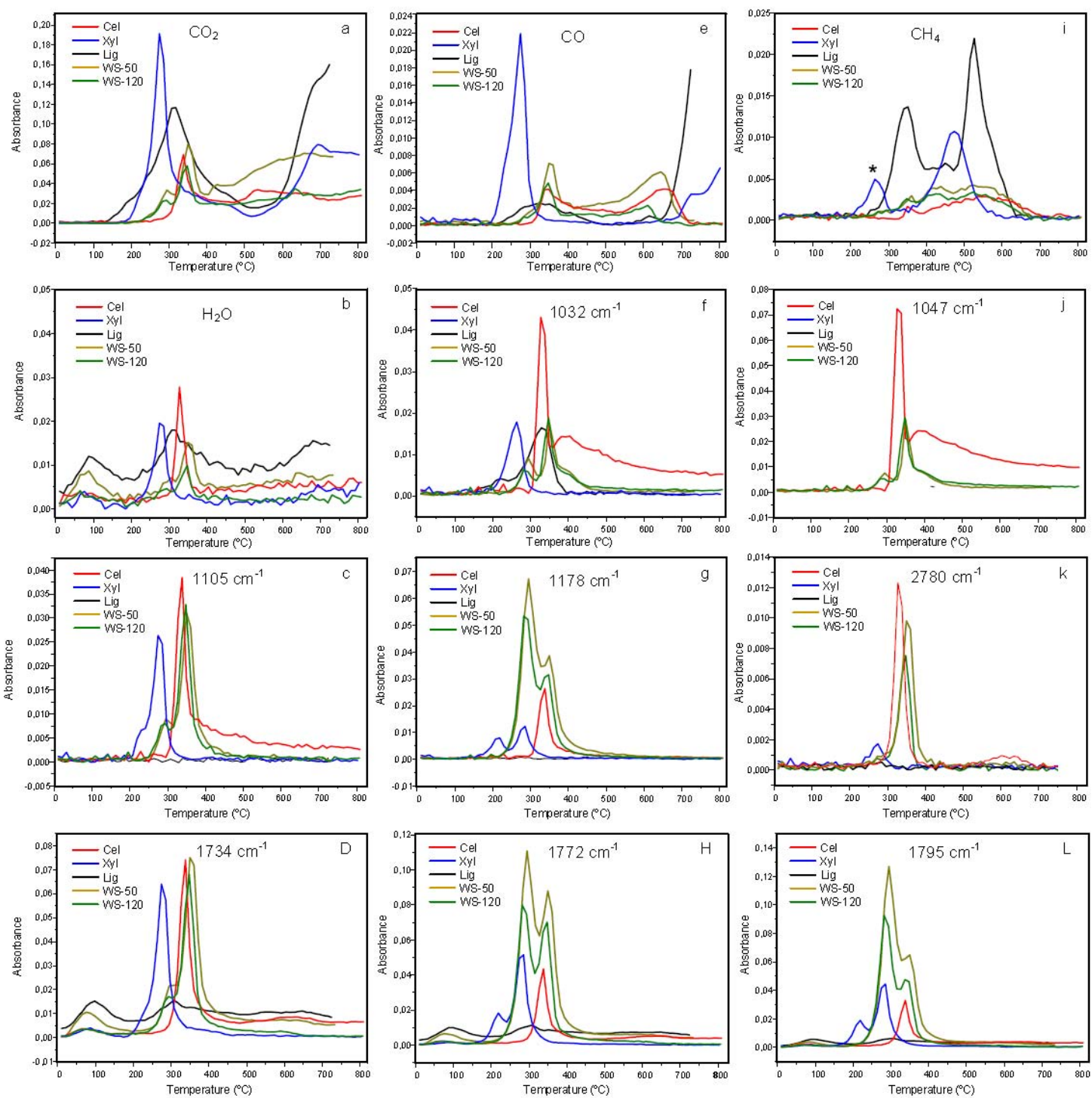

Figure 11. Comparison of the evolution of the main infrared bands of gaseous compounds evolved under nitrogen atmosphere, during decomposition of biomass components under $120 \mathrm{~mL} / \mathrm{min}$ purges, and decomposition of Washed Sisal under purges of 50 and $120 \mathrm{~mL} / \mathrm{min}$. The asterisk of Fig. 11i pyrogram on the first stage of $\mathrm{CH}_{4}$ evolution corresponds to background signal and not to methane vibration.

iii) Both in nitrogen and in air, emission of most organic compounds disappears at temperatures above $400{ }^{\circ} \mathrm{C}$. Under inert atmosphere, the evolution of gases is similar to that of pure cellulose, as it is the majority component. Emission of $\mathrm{CO}_{2}$ and $\mathrm{CO}$ start again at $400{ }^{\circ} \mathrm{C}$ due to side reactions, being the growth of $\mathrm{CO}$ intensity much slower. Emission of $\mathrm{CH}_{4}$ is also observed to increase at $400{ }^{\circ} \mathrm{C}$, whose signal remains at a nearly constant value up to $580{ }^{\circ} \mathrm{C}$, when it began to decrease and a new increase of 
$\mathrm{CO}$ is observed. The methane signal is zero due to its transformation into $\mathrm{H}_{2}$ and $\mathrm{C}$, at about $700{ }^{\circ} \mathrm{C}$ for a nitrogen flow of $50 \mathrm{~mL} / \mathrm{min}$, and $650{ }^{\circ} \mathrm{C}$ for $120 \mathrm{~mL} / \mathrm{min}$ of $\mathrm{N}_{2}$ (Fig. 11I). The $\mathrm{CO}_{2}$ and $\mathrm{CO}$ reach maximum intensity at around $660{ }^{\circ} \mathrm{C}$ with a flow of $50 \mathrm{~mL} / \mathrm{min}$, and around 630 and $610^{\circ} \mathrm{C}$ with a flow of $120 \mathrm{~mL} / \mathrm{min}$ (Fig. 11A and 11E). These temperatures nearly match the DTA exotherm peaks at 650 and $635^{\circ} \mathrm{C}$ for $50 \mathrm{~mL} / \mathrm{min}$ and $120 \mathrm{~mL} / \mathrm{min}$, respectively (Table 2).

In air, combustion occurs and maximum $\mathrm{CO}_{2}$ emission, accompanied by $\mathrm{H}_{2} \mathrm{O}$ and $\mathrm{CO}$, is observed at the maximum rate of mass loss, at around 440 and $430{ }^{\circ} \mathrm{C}$ for 50 and $120 \mathrm{~mL} / \mathrm{min}$ flow rate, respectively (Fig. 10D). The emission of $\mathrm{CO}_{2}$ continues to $500-550{ }^{\circ} \mathrm{C}$, presenting a small relative maximum in the 460 to $470{ }^{\circ} \mathrm{C}$ range. This relative maximum matches with mild exothermic processes (around $480{ }^{\circ} \mathrm{C}$ ) observed on the DTA curve, which have been associated with the decomposition of calcium oxalate and the oxidation of $\mathrm{CO}$ to $\mathrm{CO}_{2}$, as already explained. Also, it is very likely that the flue gas of residual carbon generated by the lignin contribute to these signals.

In light of the results obtained the following remarks can be made:

a. The gaseous products emitted at temperatures below $400{ }^{\circ} \mathrm{C}$ for the decomposition of sisal, are basically the same in both oxidizing and inert atmospheres, but in different proportions. During oxidative pyrolysis, these compounds are emitted to a lesser extent with respect to the $\mathrm{CO}_{2}$ emitted in this stage (Table 5). The same behavior was observed in the case of pure cellulose (Table 4). However, the mass losses observed in each one of the two decomposition sub-stages (NCP and cellulose) are similar independently of the nature and flow rate of the purge considered: 17 and $60 \%$ for $50 \mathrm{~mL} / \mathrm{min}$ of air, 17.6 and $58.5 \%$ for $120 \mathrm{~mL} / \mathrm{min}$ of air, 18.5 and $63.6 \%$ for $50 \mathrm{~mL} / \mathrm{min}$ of $\mathrm{N}_{2}, 17.8$ and $59.4 \%$ for $120 \mathrm{~mL} / \mathrm{min}$ of $\mathrm{N}_{2}$ (Table 2). The effect of the oxygen proportion is perceptible in gas phase. Decomposition temperatures for both sub-stages are enough for the generated gaseous products to oxidize immediately, generating $\mathrm{CO}_{2}$, favored by the presence of steam. Thus, a higher emission of $\mathrm{CO}_{2}$ is observed under air atmosphere. With nitrogen purge, although to a lesser extent, the oxidation of volatiles is also possible. The reason is that air goes into the furnace when inserting the sample. Although a purge of nitrogen sweeps off most of the air, a little amount of oxygen may always remain in the furnace. Thus, a higher flow of inert gas is more efficient in preventing the oxidation of volatiles and also of the solid residue.

The presence of constituents as cellulose, lignin and mineral salts, would explain the different proportions of organic compounds emitted during the first sub-stage of sisal decomposition according to the kind of atmosphere used, fact not observed in pure xylan. Furthermore, the increase in the decomposition temperature of the hemicellulose could be enough to elevate the activation threshold to initiate the oxidization of volatile compounds.

b. An increased flow of purge gas does not produce any change in the nature of the flue gases. However, it exerts a number of effects in the evolution of gases, which are summarized below:

b.1. Dilution of the output gas. The FTIR spectra show, in general, that the absolute absorbance values are slightly lower in the spectra obtained at higher flow (Table 5 and Fig. 11). A greater flow rate decreases the concentration of compounds emitted. 
b.2. Decreasing the intensity of the secondary processes experienced by the volatile products, by shortening the residence times in the furnace. For example, it can be observed in Fig. 11A how a higher flow rate reduces the oxidation of the volatiles at temperatures above $450{ }^{\circ} \mathrm{C}$, and thus reducing the $\mathrm{CO}_{2}$ formation.

b.3. Advancement of the apparent temperature range in which the gases generated by side reactions are emitted (e.g., the $\mathrm{CO}$ emission above $450^{\circ} \mathrm{C}$, Fig. 11E).

b.4. As disadvantage, a higher flow carries a higher percentage of glycol condensate, increasing the infrared vibration intensity by overlapping, like methanol and formic acid signals and, even, hiding them, as occur in the case of volatiles emitted by pure cellulose.

\section{Conclusions}

TG-FTIR analysis of pure biomass components has helped to clarify the thermal decomposition phenomena of sisal fibers, both in nitrogen and air atmospheres. This analysis may be extended to other lignocellulosic fibers.

Thermal behavior of sisal is explained as a combination of its main biomass components, prevailing cellulose. The research confirms that other constituents, such as non-cellulosic polysaccharides (NCP) and mineral matter, modify the thermal behavior of the main component. The presence of pectins, hemicelluloses and inorganic elements exerts different effects on the temperature of pyrolysis and combustion of sisal cellulose. On one hand, the protective effect of the NCP explains the delay in the pyrolysis stage of it. However, in an oxidizing atmosphere, the flue gases from the NCP facilitate the oxidation of the char, thus advancing the combustion process. The hydroxyacetaldehyde detected during the pyrolysis stage of sisal cellulose, and not in pure cellulose, indicates that the interaction with other components enables cellulose decomposition through an alternative route to that of levoglucosan generation.

The hot washing reduces the range of temperature in which sisal decomposition occurs. An increased thermal stability of sisal NCP, both under inert and air atmosphere, is produced by the hot washing process due to the removing of substances from the cell walls. Furthermore, enriching the sample in cellulose produces an increase of the mass loss rate at the second sub-step of pyrolysis, a delay of the combustion process and, depending on the decomposition atmosphere, different temperature displacements. Thus, under inert atmosphere, a slight increase of the temperature at the maximum mass loss rate of cellulose decomposition $\left(\mathrm{Tb}_{\mathrm{CEL}}\right)$ is observed, due to a better packing of the cellulose crystallites and removal of inorganic salts. Under an oxidizing atmosphere, this effect is not observed and $\mathrm{Tb}_{\mathrm{CEL}}$ is shifted to lower temperatures, as cellulose depolymerization is accelerated by oxidative reactions favored in washed sisal once the protective components are removed.

Increasing the air flow produces a slight advancement of the oxidative pyrolysis and a significant advancement of combustion. Respect to the gas evolution, an increased flow results in dilution of the exhaust gases, decreasing the FTIR absorbance signals, besides reducing the intensity of the reactions of volatile products in the furnace, and advancing the apparent temperature range at which the resulting gases are emitted. 
The author M. Benítez Guerrero wishes to thank the Spanish Consejo Superior de Investigaciones Científicas (CSIC) for the awarding of a JAE pre-doctoral grant. Support from the "Laboratorio de Materiales y Superficies" (CSIC - Univ. Malaga) is acknowledged. The second author acknowledges the Spanish Ministerio de Educación y Ciencia for the MTM2008-00166 and MTM201122392 funds.

\section{References}

[1] K. Raveendran, A. Ganesh, K.C. Khilar, Pyrolysis characteristics of biomass and biomass components, Fuel, 75 (1996) 987-998.

[2] H. Yang, R. Yan, H. Chen, C. Zheng, D.H. Lee, D.T. Liang, In-depth investigation of biomass pyrolysis based on three major components: hemicellulose, cellulose and lignin, Energ. Fuel, 20 (2006) 388-393.

[3] T. Hosoya, H. Kawamoto, S. Saka, Cellulose-hemicellulose and cellulose-lignin interactions in wood pyrolysis at gasification temperature, J. Anal. Appl. Pyrol., 80 (2007) 118-125

[4] Q. Liu, Z. Zhong, S. Wang, Z. Luo, Interactions of biomass components during pyrolysis: A TG-FTIR study, J. Anal. Appl. Pyrol., 90 (2011) 213-218.

[5] K. Raveendran, A. Ganesh, K.C. Khilar, Influence of mineral matter on biomass pyrolysis characteristics, Fuel, 74 (1995) 1812-1822.

[6] G. Várhegyi, M.J. Antal, E. Jakab, P. Szabó, Kinetic modelling of biomass pyrolysis, J. Anal. Appl. Pyrol., 42 (1997) 73-87

[7] X. Guo, S. Wang, K. Wang, Q. Liu, Z. Luo, Influence of extractives on mechanism of biomass pyrolysis, J. Fuel Chem. Technol., 38 (2010) 42-46.

[8] J. Zhang, J. Luo, D. Tong, L. Zhu, L. Dong, C. Hu, The dependence of pyrolysis behavior on the crystal state of cellulose, Carbohyd. Polym., 79 (2010) 164-169.

[9] G. Várhegyi, M.G. Grønli, C.D. Blasi, Effects of sample origin, extraction, and hot-water washing on the devolatilization kinetics of Chestnut wood, Ind. Eng. Chem. Res., 43 (2004) 2356-2367.

[10] H. Yang, R. Yan, H. Chen, C. Zheng, D.H. Lee, D.T. Liang, Influence of mineral matter on pyrolysis of palm oil wastes, Combust. Flame, 146 (2006) 605-611.

[11] A.N. Shebani, A.J.V. Reenen, M. Meincken, The effect of wood extractives on the thermal stability of different wood species. , Thermochim. Acta, 471 (2008) 43-50.

[12] B.M. Jenkins, R.R. Bakker, J.B. Wei, On the properties of washed straw, Biomass Bioenerg., 10 (1996) 177-200.

[13] S.Q. Turn, M. Kinoshita, D.M. Ishimura, Removal of inorganic constituents of biomass feedstocks by mechanical dewatering and leaching, Biomass Bioenerg., 12 (1997) 241-252.

[14] S. Arvelakis, E.G. Koukios, Physicochemical upgrading of agroresidues as feedstocks for energy production via thermochemical conversion methods, Biomass Bioenerg., 22 (2002) 331-348.

[15] R.R. Frank, Bast and other plant fibers, Woodhhead Publishing Ltd \& CRC Press, AbingtonCambridge, 2005.

[16] L.L. Escamilla-Treviño, Potential of plants from the genus agave as bioenergy crops, Bioenerg. Res., 5 (2012) 1-9.

[17] Y. Li, Y.-W. Mai, L. Ye, Sisal fibre and its composites: a review of recent developments, Compos. Sci. Technol., 60 (2000) 2037-2055.

[18] R.D. Tolêdo-Filho, K. Ghavami, G.L. England, K. Scrivener, Development of vegetable fibremortar composites of improved durability, Cement Concrete Comp., 25 (2003) 185-196.

[19] J. Wei, C. Meyer, Improving degradation resistance of sisal fiber in concrete through fiber surface treatment, Appl. Surf. Sci., 289 (2014) 511-523.

[20] K.L. Fung, X.S. Xing, R.K.Y. Li, S.C. Tjong, Y.-W. Mai, An investigation on the processing of sisal fibre reinforced polypropylene composites Compos. Sci. Technol., 63 (2003) 1255-1258.

[21] S. Kaewkuk, Effect of heat treated sisal fiber on physical properties of polypropylene composites, Adv. Mater. Res., 123-125 (2010) 1123-1126.

[22] A. El-Sabbagh, Effect of coupling agent on natural fibre in natural fibre/polypropylene composites on mechanical and thermal behaviour, Compos. Part B-Eng., 57 (2014) 126-135.

[23] G. Marques, A. Gutiérrez, J.C.d. Río, D.V. Evtuguin, Acetylated heteroxylan from Agave sisalana and its behavior in alkaline pulping and TCF/ECF bleaching, Carbohyd. Polym., 81 (2010) 517-523. 
[24] D. Stewart, A. Azzinib, A.T. Hall, I.M. Morrison, Sisal fibres and their constituent no-cellulosic polymer, Ind. Crop Prod., 6 (1997) 17-26.

[25] J.C.d. Río, A. Gutiérrez, I.M. Rodríguez, D. Ibarra, A.T. Martínez, Composition of non-woody plant lignins and cinnamic acids by Py-GC/MS, Py/TMAH and FT-IR, J. Anal. Appl. Pyrol., 79 (2007) 39-46.

[26] A. Gutiérrez, I.M. Rodríguez, J.C.d. Río, Chemical Composition of lipophilic extractives from sisal (Agave sisalana) fibers, Ind. Crop Prod., 28 (2008) 81-87.

[27] B.C. Barkakaty, Some structural aspects of sisal fibers, J. Appl. Poly. Sci., 20 (1976) 2921-2940

[28] A. Bismarck, S. Mishra, T. Lampke, Plant fibers as reinforcement for green composites, in: A.K. Mohanty, M. Misra, L.T. Drzal (Eds.) Natural fibers, biopolymers, and biocomposites, CRC Press, Florida, 2005, pp. 37-108.

[29] J. Biagiotti, D. Puglia, J.M. Kenny, A review on natural fibre-based composites. Part I: structure, processing and properties of vegetable fibres, J. Nat. Fibers, 1 (2004) 37-68.

[30] N. Chand, S. Sood, D.K. Singh, P.K. Rohatgi, Structural and thermal studies on sisal fibre, J. Therm. Anal., 32 (1987) 595-599.

[31] C. Yi, L. Tian, Y. Tong, W. Xu, Thermal stability and mechanical properties of sisal in cycle process, J. Therm. Anal. Calorim., 94 (2008) 129-135.

[32] D. Saikia, Investigations on structural characteristics, thermal stability and hygroscopicity of sisal fibers at elevated temperatures, Int. J. Thermophys., 29 (2008) 2215-2225.

[33] A.R. Martin, M.A. Martins, O.R.R.F.d. Silva, L.H.C. Mattoso, Studies on the thermal properties of sisal fiber and its constituents, Thermochim. Acta, 506 (2010) 14-19.

[34] J.C.d. Río, A. Gutiérrez, A.T. Martínez, Identifying acetylated lignin units in non-wood fibers using pyrolysis-gas chromatografy/mass spectrometry, Rapid Commun. Mass Sp., 18 (2004) 1181-1185.

[35] R. Bassilakis, R.M. Carangelo, M.A. Wójtowicz, TG-FTIR analysis of biomass pyrolysis, Fuel, 80 (2001) 1765-1786.

[36] B.S. Souza, A.P.D. Moreira, A.M.R.F. Teixeira, TG-FTIR coupling to monitor the pyrolysis products from agricultural residues, J. Therm. Anal. Calorim., 97 (2009) 637-642.

[37] S.B. Lee, O. Fasina, TG-FTIR analysis of switchgrass pyrolysis, J. Anal. Appl. Pyrol., 86 (2009) 3943.

[38] L. Segal, An empirical method for estimating the degree of crystallinity of native cellulose using the X-ray diffractometer, Text. Res. J., 29 (1959) 786-794.

[39] F. Shafizadeh, A.G.W. Bradbury, Thermal degradation of cellulose in air and nitrogen at low temperatures, J. Anal. Appl. Pyrol., 23 (1979) 1431-1442.

[40] F. Shafizadeh, Y. Sekiguchi, Oxidation of chars during smoldering combustion of cellulosic materials, Combust. Flame, 55 (1984) 171-179.

[41] O. Faix, E. Jakab, F. Till, T. Székely, Study on low mass thermal degradation products of milled wood lignins by thermogravimetry-mass-spectrometry, Wood Sci. Technol., 22 (1988) 323-334.

[42] H. Yang, R. Yan, H. Chen, D.H. Lee, C. Zheng, Characteristics of hemicellulose, cellulose and lignin pyrolysis, Fuel, 86 (2007) 1781-1788.

[43] R. Ball, A.C. McIntosh, J. Brindley, Feedback processes in cellulose thermal decomposition: implications for fire-retarding strategies and treatments, Combust.Theor. Model., 8 (2004) 281-291.

[44] D.K. Shen, S. Gua, A.V. Bridgwater, The thermal performance of the polysaccharides extracted from hardwood: cellulose and hemicellulose, Carbohyd. Polym., 82 (2010) 39-45.

[45] G. Várhegyi, E. Jakab, M.J. Antal, Is the Broido-Shafizadeh model for cellulose true?, Energ. Fuel, 8 (1994) 1345-1352.

[46] E. Jakab, O. Faix, F. Till, Thermal decomposition of milled wood lignins studied by thermogravimetry/mass spectrometry, J. Anal. Appl. Pyrol., 40-41 (1997) 171-186.

[47] T. Fisher, M. Hajaligol, B. Waymack, D. Kellogg, Pyrolysis behavior and kinetics of biomass derived materials, J. Anal. Appl. Pyrol., 62 (2002) 331-349.

[48] I. Milosavljevic, V. Oja, E.M. Suuberg, Thermal effects in cellulose pyrolysis: Relationship to char formation processes, Ind. Eng. Chem. Res., 35 (1996) 653-662.

[49] X. Xie, B. Goodell, D. Zhang, D.C. Nagle, Y. Qian, M.L. Peterson, J. Jellison, Characterization of carbons derived from cellulose and lignin and their oxidative behaviour, Bioresource Technol., 100 (2009) 1797-1802.

[50] C.D. Blasi, Combustion and gasification rates of lignocellulosic chars, Prog. Energ. Combust., 35 (2009) 121-140.

[51] R.M. Rowell, R. Pettersen, J.S. Han, J.S. Rowell, M.A. Tshabalal, Cell wall chemistry, in: R.M. Rowell (Ed.) Handbook of wood chemistry and wood composites, CRC Press, Florida, 2005, pp. 35-74.

[52] C.D. Blasi, Modelling chemical and physical processes of wood and biomass pyrolysis, Prog. Energ. Combust., 34 (2008) 47-90. 
[53] V. Tihay, P. Gillard, Pyrolysis gases released during the thermal decomposition of three Mediterranean species, J. Anal. Appl. Pyrol., 88 (2010) 168-174.

[54] R. Bilbao, J.F. Mastral, M.E. Aldea, J. Ceamanos, The influence of the percentage of oxygen in the atmosphere on the thermal decomposition of lignocellulosic materials, J. Anal. Appl. Pyrol., 42 (1997) 189-202.

[55] Y. Chen, J. Duan, Y.H. Luo, Investigation of agricultural residues pyrolysis behavior under inert and oxidative conditions, J. Anal. Appl. Pyrol., 83 (2008) 165-174.

[56] T. Sebio-Puñal, S. Naya, J. López-Beceiro, J. Tarrío-Saavedra, R. Artiaga, Thermogravimetric analysis of wood, holocellulose, and lignin from five wood species, J. Therm. Anal. Calorim., 109 (2012) $1163-1167$.

[57] C.D. Blasi, C. Branca, G. D'Errico, Degradation characteristics of straw and washed straw, Thermochim. Acta, 364 (2000) 133-142.

[58] M. Stenseng, A. Jensen, K.D. Johansen, Investigation of biomass pyrolysis by thermogravimetric analysis and differential scanning calorimetry, J. Anal. Appl. Pyrol., 58-59 (2001) 765-780.

[59] P.T. Williams, P.A. Horne, The role of metal salts in the pyrolysis of biomass, Renew. Energ., 4 (1994) 1-13.

[60] S. Li, J. Lyons-Hart, J. Banyasz, K. Shafer, Real-time evolved gas analysis by FTIR method: an experimental study of cellulose pyrolysis, Fuel, 80 (2001) 1809-1817.

[61] D.K. Shen, S. Gu, A.V. Bridgwater, Study on the pyrolytic behaviour of xylan-based hemicellulose using TG-FTIR and Py-GC-MS, J. Anal. Appl. Pyrol., 87 (2010) 199-206.

[62] Y. Wu, Z. Zhao, H. Li, F. He, Low temperature pyrolysis characteristics of major components of biomass, J. Fuel Chem. Technol., 37 (2009) 427-432.

[63] R. Artiaga, R. Cao, S. Naya, B. González-Martín, J.L. Mier, A. García, Separation of overlapping processes from TGA data and verification by EGA, J. ASTM Int., (2005).

[64] A. Demirbas, Mechanisms of liquefaction and pyrolysis reactions of biomass, Energ. Convers. Manage., 41 (2000) 633-646.

[65] J. Piskorz, D.S.A.G. Radlein, D.S. Scott, S. Czernik, Pretreatment of wood and cellulose for production of sugars by fast pyrolysis, J. Anal. Appl. Pyrol., 16 (1989) 127-142.

[66] F. Shafizadeh, Pyrolysis and combustion of cellulosic materials, in: M.L. Wolfrom, R.S. Tipson (Eds.) Advances in carbohydrate chemistry, Academic Press, New York, 1968, pp. 419-474.

[67] D.K. Shen, S. Gu, The mechanism for thermal decomposition of cellulose and its main products, Bioresource Technol., 100 (2009) 6496-6504.

[68] F. Shafizadeh, Introduction to pyrolysis of biomass, J. Anal. Appl. Pyrol., 3 (1982) 283-305.

[69] D. Radlein, J. Piskorz, D.S. Scott, Fast pyrolysis of natural polysaccharides as a potencial industrial process, J. Anal. Appl. Pyrol., 19 (1991) 41-63.

[70] T. Hosoya, H. Kawamoto, S. Saka, Different pyrolytic pathways of levoglucosan in vapor- and liquid/solid-phases, J. Anal. Appl. Pyrol., 83 (2008) 64-70.

[71] S. Wang, K. Wang, Q. Liu, Y. Gu, Z. Luo, K. Cen, T. Fransson, Comparison of the pyrolysis behavior of lignins from different tree species, Biotechnol. Adv., 27 (2009) 562-567.

[72] D. Ferdous, A.K. Dalai, S.K. Bej, R.W. Thring, N.N. Bakhshi, Production of $\mathrm{H}_{2}$ and medium Btu gas via pyrolysis of lignins in a fixed-bed reactor, Fuel Process.Technol., 70 (2001) 9-26.

[73] R.A. Fenner, J.O. Lephardt, Examination of thermal decomposition of kraft pine lignin by FTIR evolved gas analysis, J. Agric. Food Chem., 29 (1981) 846-849

[74] W.F. DeGroot, W.P. Pan, M.D. Rahman, G.N. Richards, First chemical events in pyrolysis of wood, J. Anal. Appl. Pyrol., 13 (1988) 221-231. 